DOI:10.2151/jmsj.87.57

\title{
A Nonclassical Gust Front and a Solitary Wave Embedded within a Typhoon as Observed with Doppler Radar and Wind Profiler
}

\author{
Ahoro ADACHI and Takahisa KOBAYASHI \\ Meteorological Research Institute, Tsukuba, Japan \\ (Manuscript received 3 September 2007, in final form 11 October 2008)
}

\begin{abstract}
Observations from a Doppler radar, a wind profiler, and a meteorological tower were used to study the evolution of two thin-line echoes that were observed in the radar reflectivity field over the Kanto Plain of Japan as Typhoon Higos (0221) passed in October 2002. Both thin-line echoes were accompanied by gusty winds and followed by cold airflows, and both passed the field site of the Meteorological Research Institute (MRI) in Tsukuba, Japan. Data from the MRI instrument array and from a surface observation network revealed that the first thinline echo was caused by a gust front, and the second thin-line echo was caused by a solitary wave.

Although it was demonstrated that the first thin-line echo was due to a gust front, this gust front could not be categorized as a so-called thunderstorm gust front because it had no parent thunderstorm; rather, Doppler radar and wind profiler observations suggested that both relatively strong $\left(\sim 4 \mathrm{~m} \mathrm{~s}^{-1}\right)$ downdrafts and large momentum transported by the downdrafts from aloft $(\sim 4 \mathrm{~km})$ to lower levels produced and enhanced near-surface winds behind the gust front. In contrast, the solitary wave associated with the second thin-line echo likely developed as another gust front that generated from an outer rainband to the south of the typhoon center met a stable layer formed by the cold outflow behind the gust front associated with the first thin-line echo. The ducting mechanism that enabled the solitary wave to propagate was also revealed from the wind profiler and radiosonde measurements.
\end{abstract}

\section{Introduction}

Hurricanes (or typhoons) are among the most destructive and lethal of all natural disasters, and are accompanied by violent winds and heavy rainfall. Most damage and loss of life results from hurricane-force winds and wind-induced storm surges (e.g., Emanuel et al. 2006; Hayashi 2008; Muramatsu 2008). Hurricane winds are enhanced locally when tornadoes and/or gust fronts develop within a hurricane and cause great damage to surface structures, because the high winds associated with tornadoes and/or gust fronts enhance gusts in hurricanes (Lander and Guard 2001) on or near the ground. Although studies on tornadoes in hurricanes are

Corresponding author: Ahoro Adachi, Meteorological Research Institute, 1-1 Nagamine, Tsukuba, 305-0052, Japan.

E-mail: aadachi@mri-jma.go.jp

(C) 2009, Meteorological Society of Japan common (e.g., Smith 1965; Novlan and Gray 1974; McCaul and Weisman 1987; Saito 1992; Hagemeyer 1997), studies on hurricane gust fronts are limited. Such studies are rare because in many cases hurricane gust fronts may be too shallow to detect (Powell 1990).

The low-level outflow from thunderstorms (or convective storms) is called the thunderstorm gust front, or simply the gust front (Wakimoto 1982). Thunderstorm gust fronts have been studied observationally with in situ measurements (e.g., Goff 1976) or remote sensors (e.g., Wakimoto 1982; Klingle et al. 1987; Mueller and Carbone 1987; Mahoney 1988) and also through numerical modeling (e.g., Droegemeier and Wilhelmson 1987; Crook and Tuttle 1994) and laboratory simulations (e.g., Simpson 1997). Studies have shown that strong cold downdrafts within or beneath thunderstorms are deflected laterally upon reaching the ground and produce cold-air outflow, whose pe- 
riphery is a gust front that propagates horizontally away from the storm (e.g., Martner 1997). Sublimation and/or melting and evaporation of hydrometeors falling through unsaturated air, precipitation drag, and vertical perturbation pressure gradients are all factors that may enhance downdraft development (Corfidi 2003). The main sources of the strong downdrafts are hydrometeor evaporation, i.e., convective downdrafts (Willoughby et al. 1984; Houze 1993), and precipitation drag (Wakimoto 1982). Wakimoto (2003) provides recent reviews of observational and theoretical research on the convective downdrafts and gust fronts.

Recent studies have shown that momentum transfer by downdrafts also contributes damaging winds associated with gust fronts. Corfidi (2003) found that momentum transfer from aloft by the downdrafts in convective storms increases the propagation speed of the gust fronts by analyzing nearly 50 mesoscale convective systems (MCSs). Rapidly moving gust fronts may be associated with damaging winds. Moreover, Kuchera and Parker (2006) showed that convectively driven downdrafts are one of the major factors that are favorable for strong wind fields in the lowest few kilometers to produce damaging winds at the surface by momentum transfer through numerical model analyses associated with over 7000 damaging wind reports.

Convective downdrafts are also responsible for the hurricane gust fronts. Willoughby et al. (1984) presented that mesoscale convective downdrafts in a rainband outside the eyewall can form gust fronts that flow away from the convection and propagate both toward and away from the hurricane center through a numerical model. In contrast, Powell (1990) investigated hurricane rainbands with the airborne Doppler radar and found from 38 measured drafts that convective downdrafts are preferentially located on the inner side of the rainband and occasionally spread out at the surface as a gust front, which propagates toward the center of the hurricane. However, the contribution of momentum transport by the downdrafts to the generation of hurricane gust fronts has not been reported despite the large momentum aloft in hurricanes.

Typhoon Higos (0221) passed across the Kanto Plain of Japan in October 2002. The Doppler radar at the Meteorological Research Institute (MRI) observed two thin-line echoes propagating in the radar reflectivity field associated with the typhoon. Thin-line echo is defined as a narrow radar echo in the horizontal reflectivity field indicating a bound- ary across which a density or moisture discontinuity exists (Glickman 2000). Both lines passed the MRI field site in Tsukuba, Japan, and peak surface wind gusts at the site were $31.6 \mathrm{~m} \mathrm{~s}^{-1}$ and $17.6 \mathrm{~m} \mathrm{~s}^{-1}$ for the first and second echoes, respectively.

Similar thin-line echoes are often observed with gust fronts (e.g., Wilson and Schreiber 1986; Friedrich et al. 2005). However, gust fronts are not the only causes of thin-line echoes (Klingle et al. 1987), so this is not the proof that such echoes are due to gust fronts. Indeed, other boundaries such as gravity waves sometimes show similar features (e.g., Koch and Clark 1999). In this paper, thus, we describe the evolution and reveal the causes of two thin-line echoes that occurred as Typhoon Higos passed using data from the MRI instrument array and from surface observations. We especially focus on the contribution of momentum transport by the downdrafts to the generation of the surface wind gusts associated with the thin-line echo.

This paper is organized as follows. Section 2 describes the instruments used. Section 3 presents an overview of the synoptic and mesoscale environments in which the thin-line echoes developed. In Section 4, we use tower and wind profiler observations to analyze the vertical structures of the gusty winds and the post-frontal cold airflows. Section 5 describes specific characteristics and causes of the two thin-line echoes.

\section{Data and methodology}

The MRI operates a 5.7-cm-wavelength Doppler radar that is mounted on top of the MRI building. Reflectivity and mean radial Doppler velocity in the operational data products were used in this study. The Doppler radar was operated in reflectivity mode with a long pulse repetition frequency (PRF) and in velocity mode with dual PRF, in which the PRF is switched every 32 pulses $\left(1^{\circ}\right.$ in azimuth) to dealias the Doppler velocity data. Table 1 lists operating parameters for the MRI Doppler radar system.

The Doppler radar was operated in volume-scan mode with about 6-min intervals between scans. The rotation rate was determined from the pulse repetition rate such that the azimuthal spacing was $1^{\circ}$ after linear sampling. The scan elevation sequence was $0.3^{\circ}, 0.6^{\circ}$ and $1.0^{\circ}$ in the reflectivity mode followed by the velocity mode at $0.6^{\circ}, 1.0^{\circ}$, $1.6^{\circ}, 2.3^{\circ}, 3.2^{\circ}, 4.2^{\circ}, 5.4^{\circ}, 6.8^{\circ}, 8.7^{\circ}, 12.0^{\circ}, 15.0^{\circ}$, and $20.0^{\circ}$. Radar data were interpolated to a 
Table 1. Parameters of the MRI Doppler Radar

\begin{tabular}{ll}
\hline Frequency & $5260 \mathrm{MHz}$ \\
Peak power & $250 \mathrm{~kW}$ \\
Beam width & $1.01^{\circ}$ \\
Unambiguous range & $500 \mathrm{~km}$ (for the \\
& reflectivity mode) \\
& $160 \mathrm{~km}$ (for the velocity \\
& mode) \\
No. of range gates & 1600 \\
Range gate spacing & $250 \mathrm{~m}$ \\
Azimuthal spacing & $1.0^{\circ}$ \\
Pulse repetition frequency & $300 \mathrm{~Hz}$ (for the \\
& reflectivity mode) \\
& $940 / 752 \mathrm{~Hz}$ (for the \\
Nyquist velocities & velocity mode) \\
Maximum unfolding velocity & $13.4 / 10.7$ m s ${ }^{-1}$ \\
Rotation rate & $53.6 \mathrm{~m} \mathrm{~s}^{-1}$ \\
& $9.4^{\circ} \mathrm{s}^{-1}$ (for the \\
& reflectivity mode) \\
& $\sim 27^{\circ} \mathrm{s}^{-1}$ (for the \\
No. of linear samples & velocity mode) \\
Reflectivity resolution & 32 \\
Radial velocity resolution & $0.5 \mathrm{dBZ}^{-1}$ \\
Temporal resolution & $\sim 6 \mathrm{~min} \mathrm{~s}^{-1}$ \\
\hline
\end{tabular}

Cartesian grid using a Cressman (1959) distancedependent weighting scheme for the analysis. The horizontal and vertical resolutions in the analysis were determined by the size of the analysis region. In the three-dimensional analysis, observations from the three scans in the reflectivity mode and the last ten scans in the velocity mode (from $1.6^{\circ}$ to $20^{\circ}$ ) were used to produce the reflectivity field; observations from all scans in the velocity mode were used to produce the velocity field. Figure 1 shows the MRI Doppler radar observation area in the velocity mode at $0.6^{\circ}$ and the regions for velocity field analysis in the present study along with the location of typhoon center. Doppler radar observations at the MRI field site are complemented by a network of surface instruments, Automated Meteorological Data Acquisition System (AMeDAS) and observations from a 213-m meteorological tower and a wind profiler.

The average horizontal distance between AMeDAS stations on the Kanto Plain is about $21 \mathrm{~km}$ (Fig. 1). Each station is equipped with a thermometer and propeller-driven anemometer and reports 10-min means of temperature, wind speed and direction, and rainfall per 10-min at the end of each time interval.

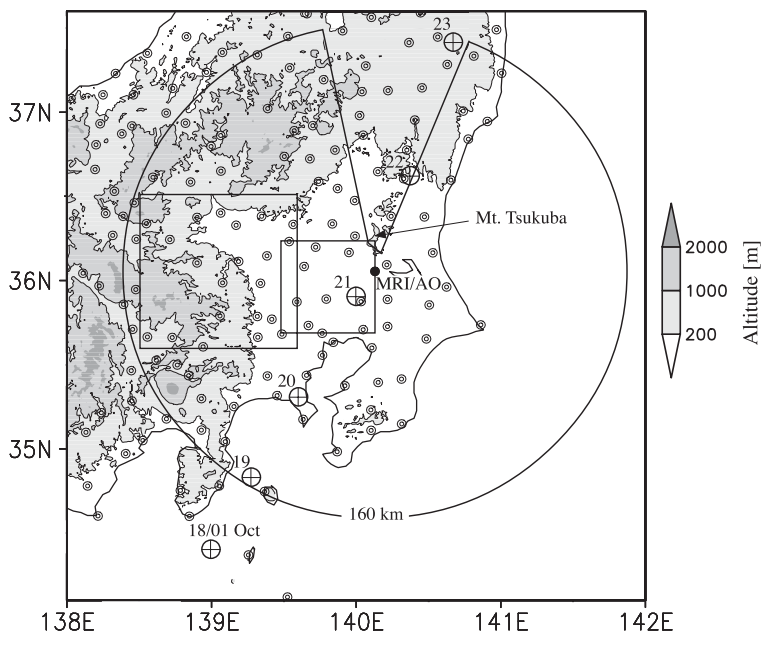

Fig. 1. The MRI Doppler radar observation area at $0.6^{\circ}$ elevation angle in velocity mode $(R=160 \mathrm{~km})$ superimposed on geographic height with the gray scale on the right. A closed circle at the center denotes the location of the MRI/AO. The deficit of the observation area to the north of the MRI is due to the radar beam blocking by Mt. Tsukuba, which is indicated by the arrow. Double circles denote the locations of AMeDAS surface observation stations, while the cross symbol within an open circle denotes the typhoon center derived from best track of Typhoon Higos (0221) between 1800 JST and 2300 JST on 1 October 2002 (JMA 2003). A large (small) square indicates the radial-velocity analysis region for Fig. 6 (Fig. 7).

Surface observations are also made with higher temporal resolution at the Aerological Observatory (AO). The AO is located about $300 \mathrm{~m}$ north of the MRI and measurements there include temperature, wind speed and direction, pressure, and precipitation. These data are averaged over $10 \mathrm{~s}$ and stored. In addition, operational radiosondes are regularly launched from the $\mathrm{AO}$, whose radiosonde site name is Tateno.

The meteorological tower is located about $300 \mathrm{~m}$ south-southwest of the MRI Doppler radar and has instrumented platforms at six levels $(10,25,50,100$, 150 , and $200 \mathrm{~m}$ above ground level) with additional instruments at the top. A thermometer, hygrometer and propeller-driven anemometer are mounted at the top and on three arms at the six levels of the tower. Data are automatically recorded from in- 
Table 2. Parameters of the MRI Wind Profiler

\begin{tabular}{ll}
\hline Frequency & $1357.5 \mathrm{MHz}$ \\
Peak power & $2 \mathrm{~kW}$ \\
Beam width & $4^{\circ}$ \\
Beam elevation & $90^{\circ}$ and $74.5^{\circ}$ \\
Pulse width & $667 \mathrm{~ns}$ \\
First range gate & $200 \mathrm{~m}$ \\
Gate spacing & $100 \mathrm{~m}$ \\
Inter-pulse period & $50 \mu \mathrm{s}$ \\
Max height sampled & $4.1 \mathrm{~km}$ \\
Max radial velocity & $\pm 17.3 \mathrm{~m} \mathrm{~s}^{-1}$ \\
Spectral points & 128 \\
No. of coherent integration & 64 \\
No. of incoherent integration & 1 \\
Pulse compression & $1 \mathrm{bit} / 8 \mathrm{bit}$ \\
Dwell time & $\sim 0.4 \mathrm{~s}$ \\
Temporal resolution & $\sim 15 \mathrm{~s}$ \\
\hline
\end{tabular}

struments mounted on the upwind arms at the six levels to remove the effects of the tower itself. Data from these instruments are averaged over $1 \mathrm{~min}$ and stored. Hanafusa et al. (1979) has provided a more detailed description of the tower and its instruments. Tower data are used to describe events in the lowest $200 \mathrm{~m}$, and wind profiler data are used to describe events above $200 \mathrm{~m}$.

The MRI wind profiler, an AR-1300B (Hashiguchi et al. 2004), is located about $300 \mathrm{~m}$ north of the tower. The wind profiler uses the Doppler beam swinging (DBS) method to estimate the wind from five beams generated in different directions by the antenna. For observations of the gusty wind events described in this study, incoherent integration was not applied (alternatively, the number of spectra averaged was one), thereby increasing the temporal resolution, which was determined not by the dwell time for each beam but rather by the time needed for signal processing and data recording. Because the observations were made during precipitation, most signals were strong enough to derive robust Doppler spectral data despite the lack of incoherent integration. This study used the four-beam method (Adachi et al. 2005) to determine the horizontal wind component. Only observations without (1-bit) pulse compression were used to calculate reflectivity. Table 2 summarizes configurations and operating parameters.

A unique capability of the wind profiler is its ability to rapidly sample both vertical and horizontal velocities in clear air (Gage 1990; Van Zandt 2000). However, because of the operating frequency, the MRI wind profiler cannot measure the

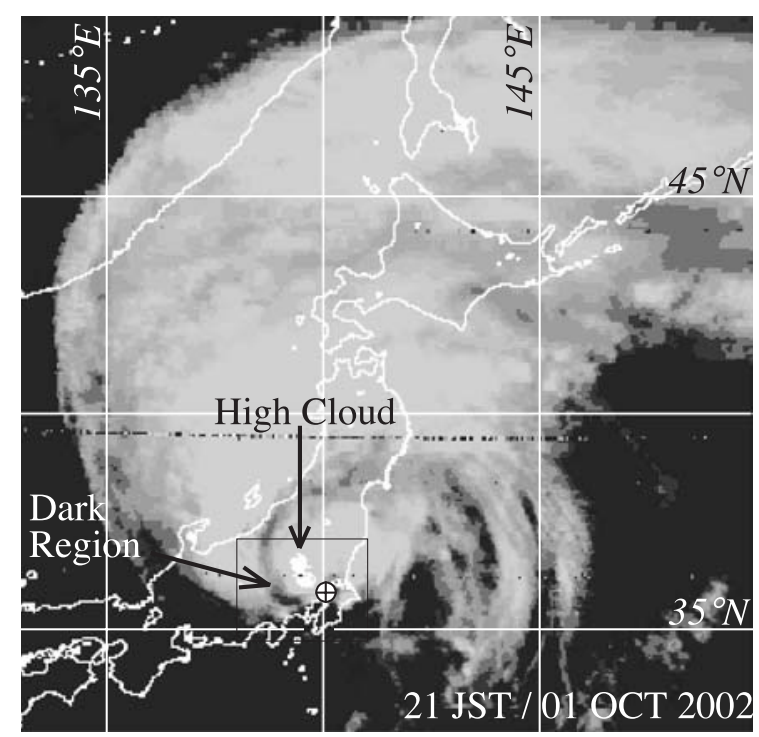

Fig. 2. GMS-5 infrared brightness temperature imagery of Typhoon Higos (0221) at 21 JST on 1 October 2002. The cross symbol within an open circle denotes the typhoon center. The downward arrow indicates the location of a high cloud $\left(T_{b}<\right.$ $215 \mathrm{~K}$ ), and the right-pointing arrow points to a dark region that includes low clouds $\left(T_{b}>263 \mathrm{~K}\right)$. The rectangle indicates the analysis area for Figs. 4 and 5.

vertical wind component during precipitation events, and instead measures the vertical velocity of falling hydrometeors (Ralph et al. 1995; Kobayashi and Adachi 2005). To circumvent this problem, vertical air motions are estimated from the reflectivities and Doppler velocities measured by the profiler with a correction for the effects of air density (see Appendix A).

\section{Overview of the thin-line echoes}

\subsection{Satellite and radiosonde observations}

Figure 2 shows Geostationary Meteorological Satellite infrared imagery at 21 JST (Japan Standard Time: $\mathrm{JST}=\mathrm{UTC}+9$ hours) on 1 October 2002. Typhoon Higos is making landfall in the observation area over eastern Japan. The rectangle highlights the study region, which includes the Kanto Plain and surrounding mountains and ocean. The center of Higos was within $3 \mathrm{~km}$ of the MRI at 2115 JST. A downward arrow points to the region of cold IR temperatures $\left(T_{b}<215 \mathrm{~K}\right)$. This region corresponds to mature convection over the 


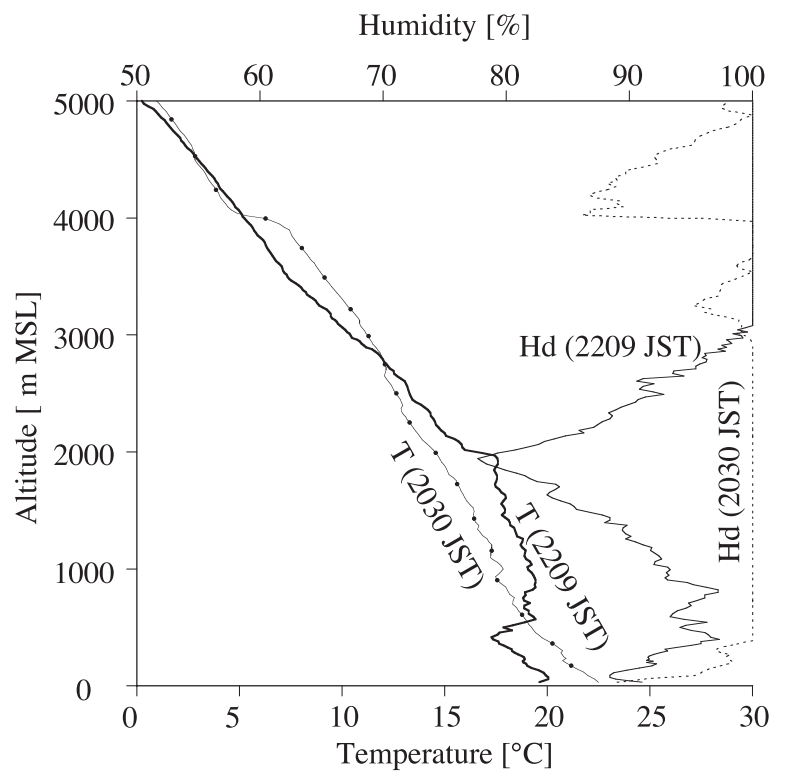

Fig. 3. Vertical structure of the lower troposphere at the MRI site derived from AO radiosonde observations on 1 October 2002. A thin line with closed circles and a thick line represent temperature $(T)$ at 2030 JST and 2209 JST, respectively. A dashed (medium-thick) line indicates humidity $(H d)$ at 2030 JST (2209 JST). The data and time are indicated along with the each sounding profile. The lowest heights of the observations are $30 \mathrm{~m}$ MSL.

Kanto Plain. The altitude of the cloud top as inferred from $T_{b}$ exceeded $14 \mathrm{~km}$. Prior hourly satellite images (not shown) indicate that this high cloud corresponded to the eyewall of Higos. The rightpointing arrow points to a dark narrow region that is to the west of the high cloud. This dark region includes a region where cloud top heights as inferred from $T_{b}$ were less than $7 \mathrm{~km}$. Note that the GMS-5 IR sensor scanned over Japan approximately 16 min before the observation time - that is, the nominal time of the satellite image (21 JST) differs from the actual scan time for lines over Japan.

Vertical soundings measured with radiosondes depict atmospheric characteristics around the typhoon. Figure 3 shows vertical profiles of temperature and humidity derived from radiosondes launched from the AO at 2030 JST and 2209 JST on 1 October. The first radiosonde was launched 45 min prior to the passage of the center of Higos, and the second radiosonde passed through the dark region. The vertical resolution of each profile averages $26 \mathrm{~m}$. Figure 3 shows a distinct change in the humidity profile between 2030 JST and 2209 JST. In the later sounding, a dry layer (relative humidity less than $90 \%$ ) was between $1000 \mathrm{~m}$ and $2500 \mathrm{~m}$. Both temperature profiles show a melting level $\left(0^{\circ} \mathrm{C}\right)$ at about $5 \mathrm{~km}$. The later $(2209 \mathrm{JST})$ temperature profiles show cooler temperatures at altitudes below $550 \mathrm{~m}$ MSL and two inversion layers at about $490 \mathrm{~m}$ MSL and $820 \mathrm{~m}$ MSL, suggesting the atmosphere was stable at low altitude. It will subsequently be shown below that this cooler temperature reflected cold airflow behind the first thin-line echo. These features will be discussed below.

\subsection{The first thin-line echo \\ a. Surface measurements and reflectivity fields}

Doppler radar data include a reflectivity field outlining the rainfall distribution over the Kanto Plain as Higos made landfall. For this radar, a $0.3^{\circ}$ elevation angle is the lowest that yields useful coverage of the analytical area because of the mountains surrounding the Kanto Plain. Mt. Tsukuba (877 m MSL, $16 \mathrm{~km}$ north of the MRI) blocks the radar beam, making observations behind it impossible even at this elevation angle (Fig. 1). Figures $4 \mathrm{a}-\mathrm{c}$ show the evolution of the reflectivity field. The shaded areas in the figures denote precipitation echoes. Surface wind vectors measured with AMeDAS are superimposed on the radar observations. The AMeDAS data reports are for the end of each 10-min averaging period and the radar data shown were observed about 5 min before the AMeDAS observations. Doppler radar data are snapshots, not averages. Dashed contours indicate terrain heights of $200 \mathrm{~m}$ MSL. The low area in the southeastern part of the figures is the Kanto Plain, surrounded by mountains and ocean (see also Fig. 1).

The predominant surface flow at 1924 JST just before the landfall of Higos was easterly from the ocean to the Kanto Plain (Fig. 4a). Three regions $\left(A_{1}, A_{2}\right.$, and $\left.B\right)$ with reflectivities exceeding $34 \mathrm{dBZ}$, corresponding to heavy precipitation, are evident in the figure. Regions $\mathrm{A}_{1}$ and $\mathrm{A}_{2}$ might be orographically forced because they extend along contours of terrain height at $200 \mathrm{~m}$. Region B might also be orographic precipitation because it is on the slope of the high mountains to the northwest, where elevations exceed $1000 \mathrm{~m}$ (Fig. 1).

After Higos made landfall, $\mathrm{A}_{2}$ moved with the typhoon (Figs. $4 \mathrm{a}-\mathrm{c}$ ) and extended into the ty- 

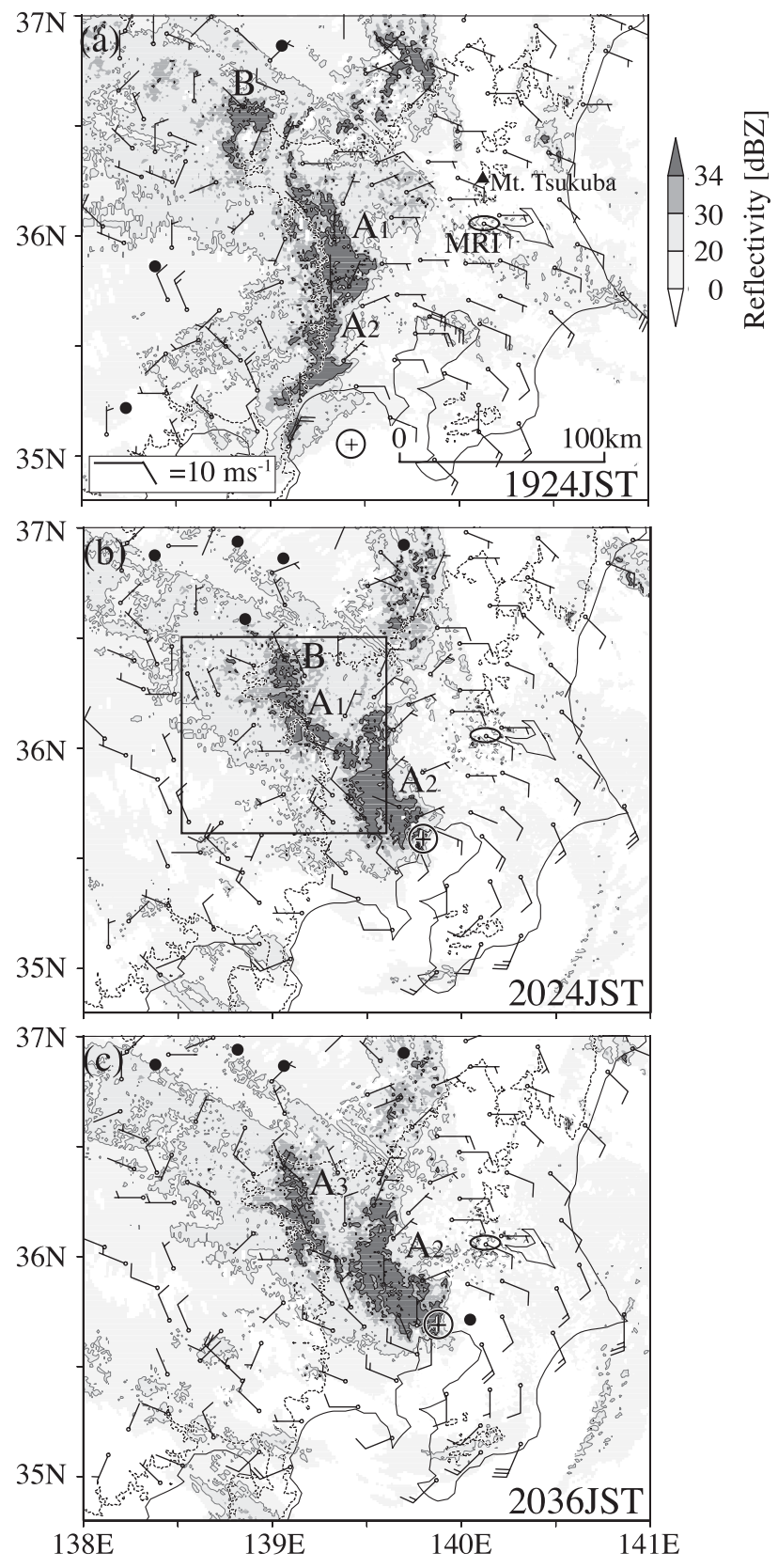

phoon center, obscuring the typhoon eye. Surface friction effects over land may also have caused the cloudiness within the eye (Yau et al. 2004). At the same time, region $\mathrm{A}_{1}$ shifted northwest along contours of terrain height at $200 \mathrm{~m}$ (Figs. $4 \mathrm{~b}$ and $4 \mathrm{c}$ ). This shift might be due to translation of $A_{1}$ and/or displacement of location favorable for terraininduced precipitation because of wind shift associated with the typhoon passage. In contrast, B moved to the southeast and intercepted $A_{1}$ (Fig.
Fig. 4. Radar reflectivity with the horizontal resolution of $1 \mathrm{~km}$ at (a) $1924 \mathrm{JST}$, (b) 2024 JST, and (c) 2036 JST on 1 October 2002. Surface winds at (a) 1930 JST, (b) 2030 JST, and (c) 2040 JST are superimposed over the reflectivity. A full wind barb is $10 \mathrm{~m} \mathrm{~s}^{-1}$; a closed circle denotes wind speeds less of than $1.0 \mathrm{~m} \mathrm{~s}^{-1}$. The gray scale on the right side of (a) represents reflectivity observed with the Doppler radar at a $0.3^{\circ}$ elevation angle. The typhoon center is denoted by the cross symbol in the open circle. The open oval in each figure marks the location of the MRI. Dashed lines in each figure are topographic contours at $200 \mathrm{~m}$, and the thick black contours represent reflectivity at $34 \mathrm{dBZ}$. $\mathrm{A}_{1}$, $\mathrm{A}_{2}, \mathrm{~A}_{3}$, and $\mathrm{B}$ in the figures indicate regions of heavy rain, and the square in (b) denotes the area in Fig. 6. 4b). Regions $A_{1}$ and $B$ then merged to form heavy precipitation region $\mathrm{A}_{3}$ (Fig. 4c). The focus below will be on the evolution of the two heavy precipitation regions $\left(\mathrm{A}_{1}\right.$ and $\left.\mathrm{B}\right)$ including the collision in the area depicted by the square in Fig. $4 \mathrm{~b}$.

Figures $5 \mathrm{a}-\mathrm{d}$ show the evolution of AMeDAS surface wind vectors and sea-level temperature. Sea-level temperature data were derived by use of the temperature profile measured with the radiosonde at 2030 JST on 1 October (Fig. 3). Tempera- 

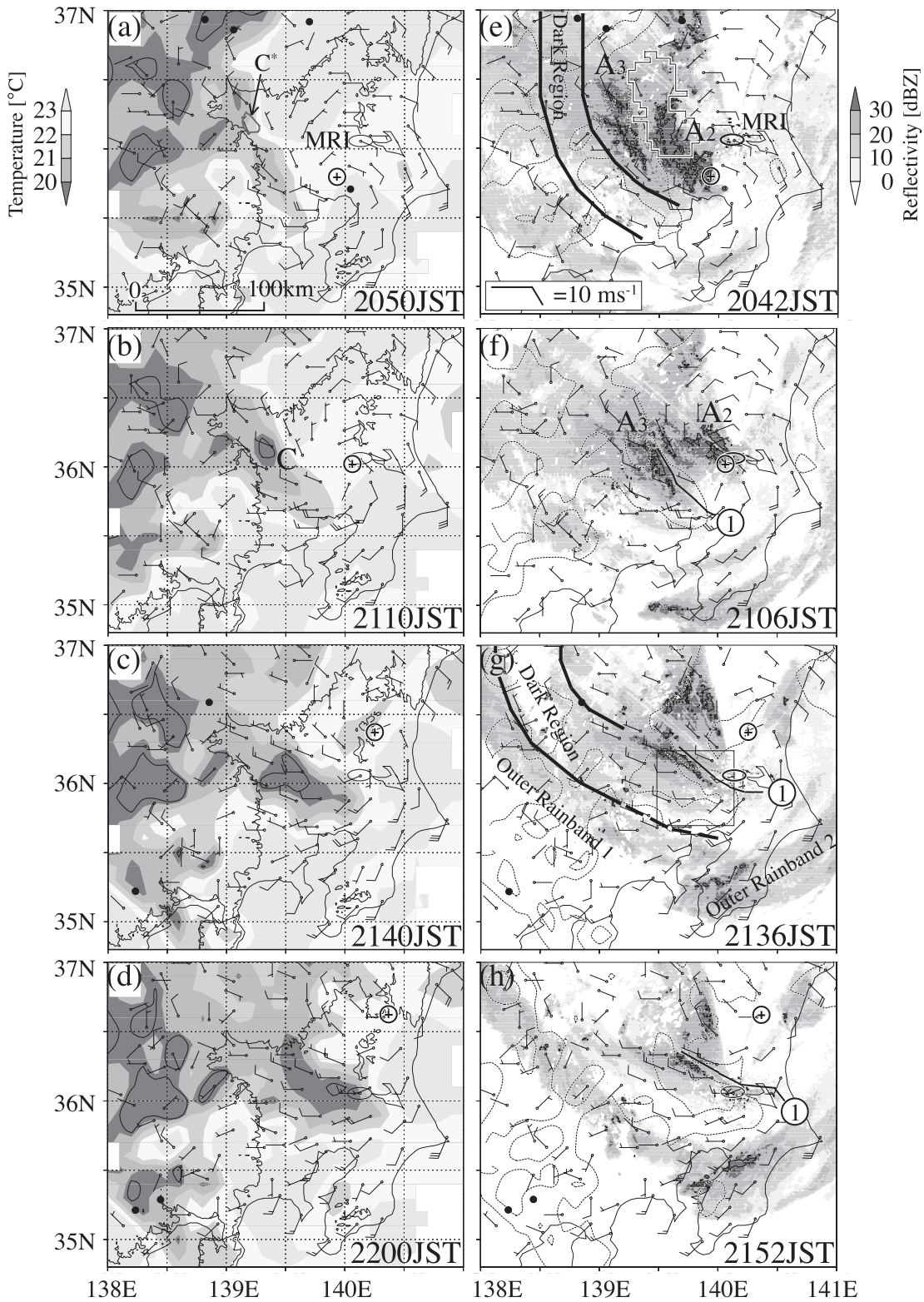

Fig. 5. Surface wind barbs superimposed on surface temperature at sea level (a)-(d) and reflectivity (e)-(h) on 1 October 2002. Observation times are shown in JST in the lower-right corner of each image. Surface wind and temperature for the reflectivity images in (e)-(h) are the same as those in (a)-(d). A full wind barb is $10 \mathrm{~m} \mathrm{~s}^{-1}$, and the closed circle indicates wind speed of less than $1.0 \mathrm{~m} \mathrm{~s}^{-1}$. The typhoon center is marked by the cross symbol within an open circle. Open ovals in (a)-(h) denote the location of the MRI. Thin black contours in (a)-(d) are the topographic contours of $200 \mathrm{~m}$; the thick black contour is the $19.5^{\circ} \mathrm{C}$ isotherm. Thin dashed contours in (e)-(h) represent temperature at sea level as in (a)-(d) but only at $20^{\circ} \mathrm{C}$ and $22^{\circ} \mathrm{C}$ for ease of viewing; the thin black contours represent reflectivity at $35 \mathrm{dBZ}$.

$\mathrm{A}_{2}$ and $\mathrm{A}_{3}$ in (e) and (f) indicate heavy rain regions, the thin line superimposed on the thick white line in (e) surrounds the high cloud in Fig. 2. A square in (g) denotes the area in Fig. 7. The thin black line with a circled 1 in (f)-(h) denotes the first thin-line echo. Thick black lines in (e) and (g) denote the edges of the dark region in satellite images scanned at 2044 JST and 2144 JST, respectively. C in (b) denotes a cool temperature region that formed behind $\mathrm{A}_{3}$, and $\mathrm{C}^{*}$ denoted by an arrow in (a) indicates an estimated location of the cold air region at the time assuming that the cold air mass less than $19.5^{\circ} \mathrm{C}$ in $\mathrm{C}$ is advected by westnorthwesterly winds at $12 \mathrm{~m} \mathrm{~s}^{-1}$ in $20 \mathrm{~min}$. 
tures over the ocean are less reliable because they were extrapolated from land surface measurements.

Doppler radar data were used to derive a reflectivity field over the Kanto Plain that complements surface measurements. Figures $5 \mathrm{e}-\mathrm{h}$ show the evolution of the reflectivity for times after those in Fig. 4. Surface wind vectors and sea-level temperatures derived from AMeDAS are superimposed on the radar observations. The temperature contours in Figs. $5 \mathrm{e}-\mathrm{h}$ are $20^{\circ} \mathrm{C}$ and $22^{\circ} \mathrm{C}$.

The predominant surface flow just after landfall was counterclockwise around the center of Higos. That flow moved warm air from the northeast and the southwest over the Kanto Plain at 2050 JST (Fig. 5a). A large temperature gradient appeared at the boundary between warm air associated with the typhoon and colder air over the northwestern part of the observational domain. Earlier AMeDAS observations (not shown) indicate that this cold air, characterized by temperatures cooler than $21^{\circ} \mathrm{C}$, covered nearly the entire observational domain at $1500 \mathrm{JST}$ on 1 October. The cooler air was subsequently eroded by warm easterly-northeasterly winds associated with Higos approaching to the Kanto Plain. Relatively cold air was also present over the western part of the Kanto Plain.

Figure 5e shows reflectivity at 2042 JST and surface wind vectors and temperature at 2050 JST. The region surrounded by a thin black line on a thick white line matches the high cloud top region in Fig. 2. The two regions of large reflectivity $(Z>35 \mathrm{dBZ})$ correspond to regions $\mathrm{A}_{2}$ and $\mathrm{A}_{3}$ defined in Fig. 4. The strongest reflectivity in region $\mathrm{A}_{2}$ was within and moved with the region of high cloud tops. Thus, region $\mathrm{A}_{2}$ likely corresponds to the region of high cloud tops. Region $\mathrm{A}_{3}$ corresponds to a relatively cold region at the surface (Fig. 5a), which may have been formed by precipitation from region $A_{3}$. However, advection from the region of cold air in the mountainous area northwest of region $\mathrm{A}_{3}$ could also have contributed to the cold air. South of regions $A_{2}$ and $A_{3}$ was a mostly rain-free region. This region matches the dark region in Fig. 2.

AMeDAS observations show the formation of a local cold region over the northwest part of the Kanto Plain by 2110 JST (region C in Fig. 5b). At the station located in C (Kumagaya station), 10min mean wind speed increased from $6 \mathrm{~m} \mathrm{~s}^{-1}$ to $12 \mathrm{~m} \mathrm{~s}^{-1}$ within $10 \mathrm{~min}$ by the time. The Kumagaya station recorded westerly winds with a peak gust of $30.8 \mathrm{~m} \mathrm{~s}^{-1}$ at 2119 JST. This local cooling formed just behind region $\mathrm{A}_{3}$ and moved with it (Figs 5c, 5d, 5g, and 5h). The temperature of the local cold air mass was cooler than that of upstream air. Indeed, region $\mathrm{C}^{*}$ in Fig. 5a, which indicates the estimated cold area at the time assuming that the cold air in $\mathrm{C}$ is advected in $20 \mathrm{~min}$ by the westnorthwesterly wind observed at the Kumagaya station at $2110 \mathrm{JST}$, shows that the corresponding region upstream is at least $1{ }^{\circ} \mathrm{C}$ warmer than the cold air expected at the time. This suggests that cold advection is unlikely to have been a primary cause of the local cold region. The area of the cold air mass expanded with time as it moved eastward (Fig. 5b and 5c), reaching the MRI at 2150-2200 JST (Fig. $5 \mathrm{~d})$. A local cold air mass less than $19.5^{\circ} \mathrm{C}$ is analyzed about $20 \mathrm{~km}$ west of the MRI at this time, corresponding to an extension of the cold air mass less than $20^{\circ} \mathrm{C}$ in the east part.

After the cold air mass formed, rain region $\mathrm{A}_{3}$ moved eastward and narrowed as it extended southeast after 2106 JST (Fig. 5f). As the cold air mass moved eastward (Fig. $5 \mathrm{c}$ ), the rain region became concentrated ahead of the cold air mass, where a large temperature gradient occurred (Fig. $5 \mathrm{~g})$. The rain region formed a thin-line echo clearly by 2119 JST; the thin-line echo was then always located at the leading edge of the moving cold air mass (Figs. $5 \mathrm{~g}$ and $5 \mathrm{~h}$ ). This association is often observed with thunderstorm gust fronts (Klingle et al. 1987). The length of the thin-line echo with reflectivities more than $20 \mathrm{dBZ}$ was about $80 \mathrm{~km}$ and width of the segment that passed the MRI was about $6 \mathrm{~km}$. These values are much smaller than those of the trailing outer rainband 1 (Fig. 5g) with a length (width) of about $300 \mathrm{~km}(27 \mathrm{~km})$. Note that the thin-line echo was located near the edge of the dark region (Fig. 5g) that corresponded to the region of low cloud tops in the satellite imagery. The region of low cloud tops overlays a region of light rain southwest of the thin-line echo ahead of the outer rainband 1 propagated northeastward (Figs. 5g and 5h). These features will be discussed below.

The thin-line echo passed the MRI at about $2150 \mathrm{JST}$, with an estimated mean propagation speed and direction of $19.5 \mathrm{~m} \mathrm{~s}^{-1}$ and $71^{\circ}$, respectively, clockwise from the north. The mean direction perpendicular to the thin-line echo, $38^{\circ}$, differs from the propagation direction. These values are determined by finding the maximum reflectivity along each cross section running orthogonal to the thin-line observed between 2136 and 2153 JST and 
then calculating the mean of the values for the segment that passed the MRI. Note that the wind direction in the cold airflow behind the thin-line echo was not perpendicular to it. Some winds were nearly parallel to the thin-line echo and showed little difference across the echo (Figs. 5g and 5h). Winds gusted to $31.6 \mathrm{~m} \mathrm{~s}^{-1}$ at the MRI just after the thin-line echo passed.

Reflectivity fields observed by Doppler radar show that the thin-line echo had some features similar to thunderstorm gust fronts. We next explore the mechanism that formed the thin-line echo associated with the gusty winds; the reflectivity and radial velocity fields measured by the Doppler radar provide clues to understanding how the gusty winds developed.

\section{b. Three-dimensional analysis of radial velocity and reflectivity fields}

Figures $6 \mathrm{a}-\mathrm{h}$ show the three-dimensional evolution of radial velocity and reflectivity fields looking south-southwest in the area depicted by a square in Figs. 1 and $4 \mathrm{~b}$. The observation time of the velocity mode with an elevation angle of $0.6^{\circ}$ is shown for each image. Figure $6 \mathrm{a}$ shows three-dimensional contours of high reflectivity $(35 \mathrm{dBZ})$ and high radial wind speeds $\left(20 \mathrm{~m} \mathrm{~s}^{-1}\right)$ at $2025 \mathrm{JST}$. The three high-reflectivity regions (regions $A_{1}, A_{2}$, and $B$ in Fig. 4b) are evident. Region $A_{1}$ merged with $B$ (Fig. 6b) to form a new high reflectivity region $A_{3}$ (Fig. 6c). The height of region $A_{3}$ decreased with time (Figs. 6d and 6e) as the thin-line echo formed (Fig. 6f). This evolution of the high-reflectivity regions agrees with those presented in Figs. 4 and 5. However, the three-dimensional analysis yields insight into the horizontal and vertical evolutions of the reflectivity and radial velocity fields. Of course, there are always some issues that arise from the difference between radial velocity observed with the Doppler radar and the actual horizontal wind speed. This issue should be kept in mind in examining the analysis presented in this study.

High winds started to develop at 2043 JST (Fig. $6 c)$ in the region of light rain (Fig. 5e) near the surface after a region of high radial wind $\left(>20 \mathrm{~m} \mathrm{~s}^{-1}\right)$ entered the region of analysis from the south at altitudes above $7 \mathrm{~km}$ (Figs. 6a-d). The size of the area of strong low-level winds increased with time as its edge moved northeast (Figs. 6d and 6e). After the edge intercepted region $\mathrm{A}_{3}$ at $2055 \mathrm{JST}, \mathrm{A}_{3}$ stretched horizontally along the leading edge of the strong low-level winds and formed the thin-line echo (Fig. 6f). Note that the region of the strong low-level winds (Fig. 6e) extends beyond the area where $A_{1}$ and $B$ are located (Figs. 6a and 6b). This feature is discussed in the following section.

The strong low-level winds terminated with the arrival of outer rainband 1 (Figs. 6g and 6h). However, high winds persisted above the outer rainband 1 after the termination of the strong low-level winds in the region of analysis. The location of the highwind region aloft changed little with time (Figs. 6c and $6 \mathrm{~g}$ ) even though the typhoon was moving away. The lowest (top) height of the strong wind region at $2153 \mathrm{JST}$ (Fig. 6g) was $3.8-4.5 \mathrm{~km}$ (7.9$9.3 \mathrm{~km})$. Note that some filaments of strong winds extended from the high-wind region aloft to the lower level. These filaments, highlighted by open ovals, occurred just before the onset (Fig. 6b) and in the development stage (2049-2101 JST) of the strong low-level winds (Fig. 6e). These filaments were also observed at 2113 JST (not shown). On the contrary, these filaments were not observed before the onset of the strong low-level winds (Fig. 6a). Unfortunately, detailed features of the filaments in the region of analysis cannot be resolved because of the limited observational resolution of the Doppler radar. However, the observational resolution of the Doppler radar is quite high near the MRI site.

Figures $7 \mathrm{a}-\mathrm{d}$ show the isosurface of strong winds with a radial velocity of $22 \mathrm{~m} \mathrm{~s}^{-1}$ from 2113 JST to 2137 JST, in the region depicted by the square in Figs. 1 and 5g, at the edge of which the Doppler radar was located. The value of $22 \mathrm{~m} \mathrm{~s}^{-1}$ was chosen to clearly separate the strong low-level winds from the high-wind region aloft. Three-dimensional contours of reflectivities are also plotted in the figures. The figures clearly show that the region of strong low-level winds propagated northeastward, which agrees with the evolution of the thin-line echo (Figs. 5f and 5g). The maximum (mean) height of the strong low-level winds is $1.8 \mathrm{~km}(1.2 \mathrm{~km})$ AGL at $2119 \mathrm{JST}$. It is also evident that the thin-line echo locates ahead of the high winds (Figs. 7a and $7 b$ ). However, the presence of a nose and/or a head, which is often observed with a gust front, is not obvious in the figures.

The base of the high-wind region aloft descended with time (Figs. 7a and 7b) and developed into two funnels, $F_{1}$ and $F_{2}$, as indicated by the red arrows in Fig. 7b, ahead of the region of strong low-level winds. The funnel $\mathrm{F}_{1}$ descended at a speed of $3.6 \mathrm{~m} \mathrm{~s}^{-1}$ and reached at an altitude of $862 \mathrm{~m}$ 

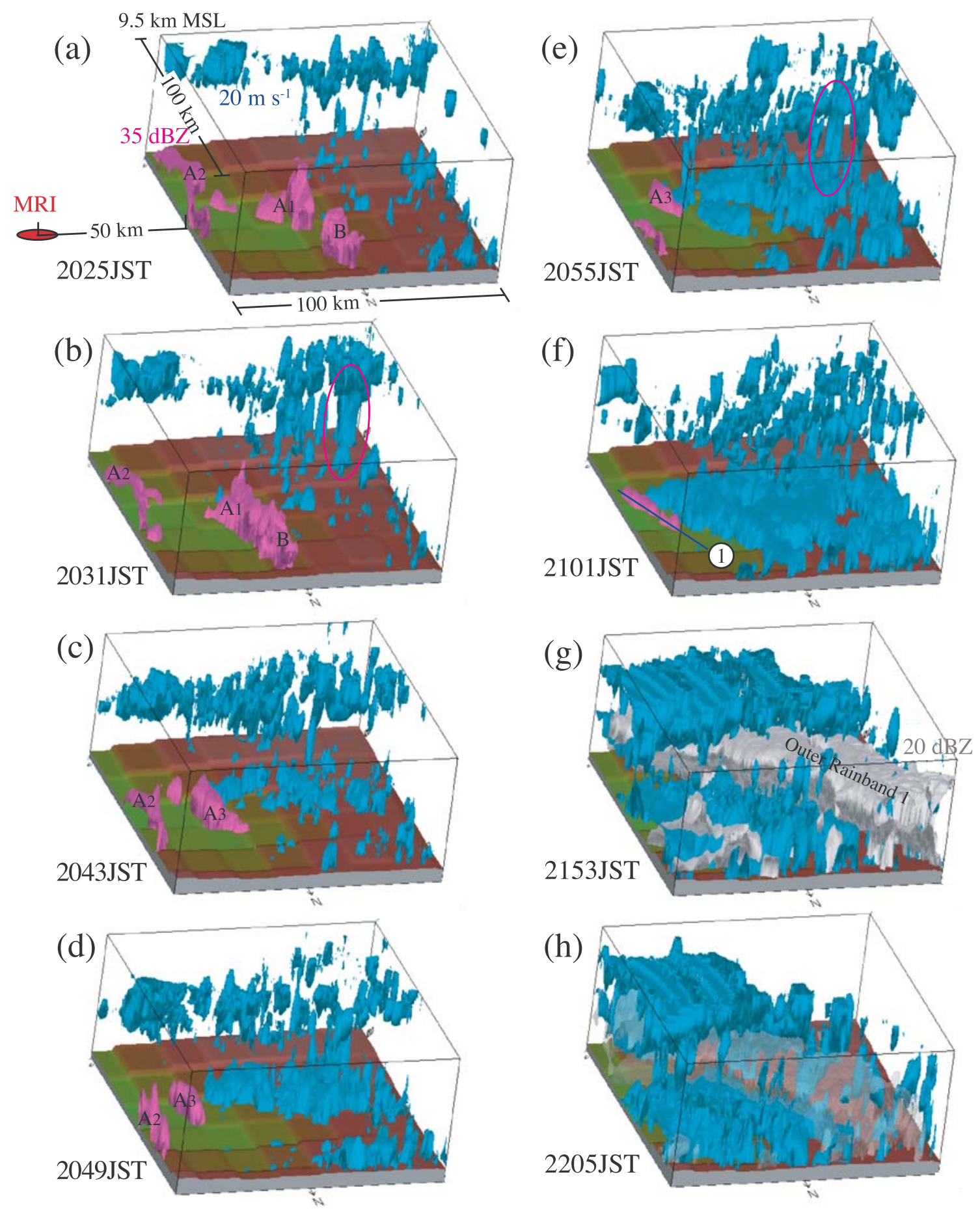

Fig. 6. Three-dimensional contours of reflectivity and high wind looking south-southwest on 1 October 2002, in the region depicted in Figs. 1 and 4b. The observation time is shown in the lower-left of each image. Dark pink surfaces in (a)-(f) denote reflectivity at $35 \mathrm{dBZ}$, while blue surfaces in each image represent radial velocities at $20 \mathrm{~m} \mathrm{~s}^{-1}$. Light gray surfaces in $(\mathrm{g})$ and $(\mathrm{h})$ represent reflectivity at $20 \mathrm{dBZ}$, which corresponds to the outer rainband 1 . The opacity of the surface for the reflectivity of $20 \mathrm{dBZ}$ in $(\mathrm{h})$ is low to reveal what is behind it, showing the termination of the strong low-level winds beneath the outer rainband 1. Open ovals in (b) and (e) denote areas of high-wind filaments. The blue line with a circled 1 in (f) denotes the first thin-line echo. A closed oval in (a) denotes the location of the MRI. The horizontal resolution is $250 \mathrm{~m}$ and vertical resolution is $1000 \mathrm{~m}$ in the figures. 


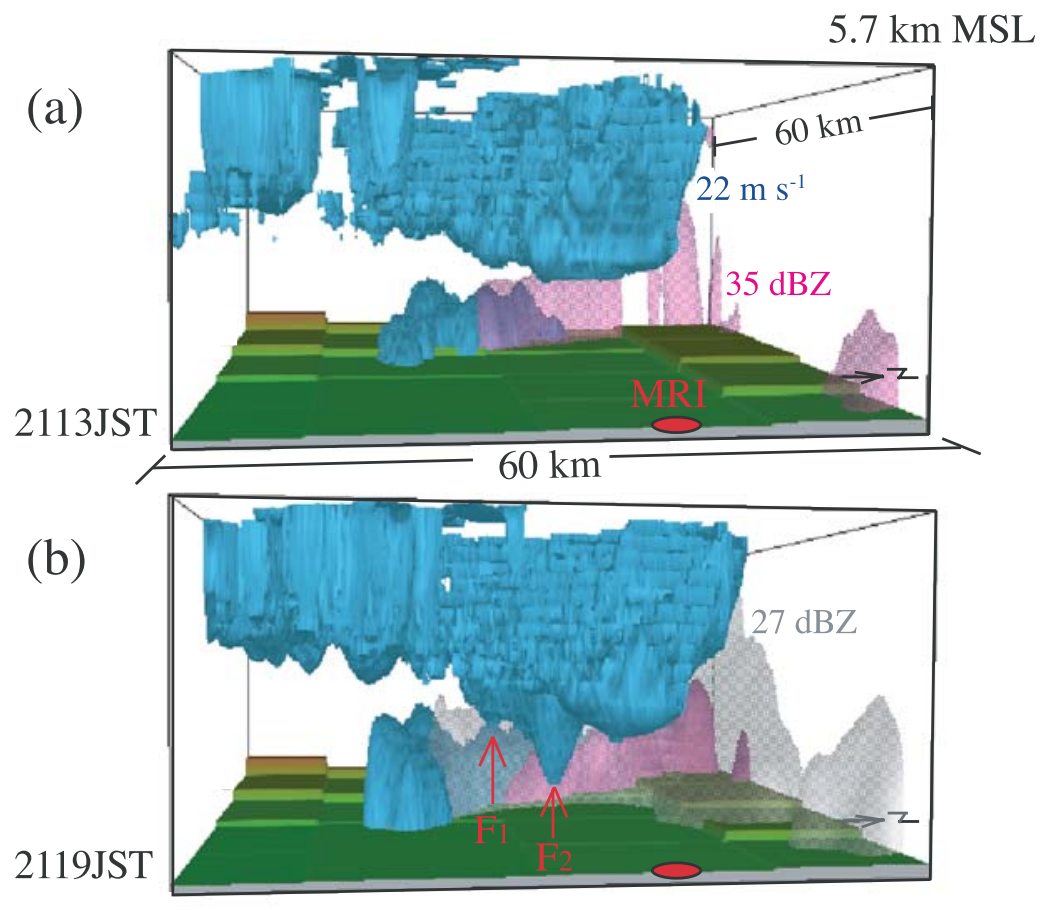

(c)

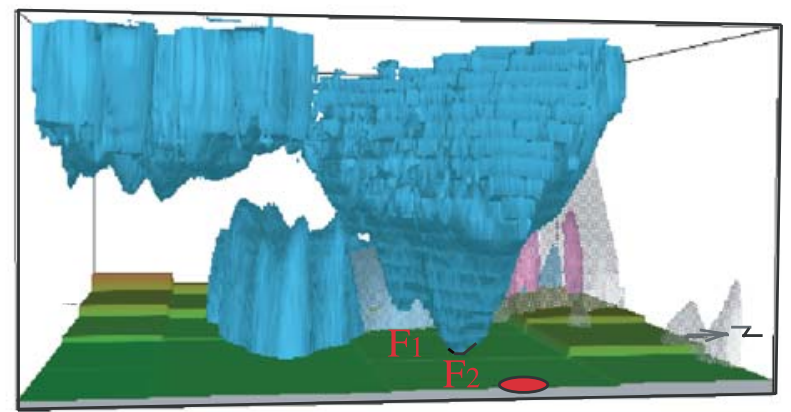

(d)

2125JST

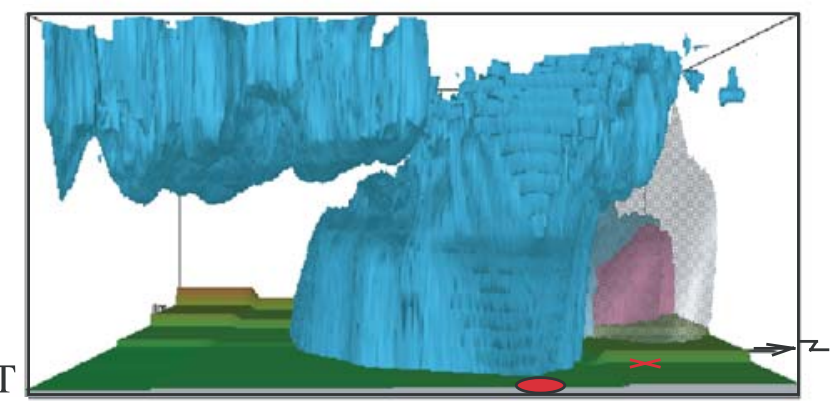

Fig. 7. Three-dimensional contours of reflectivity and high wind looking west-northwest on 1 October 2002, in the region depicted in Figs. 1 and 5g. Observation times are shown in the lower-left of each image. A closed oval in each image denotes the location of the MRI. Blue surfaces in each image represent radial velocities at $22 \mathrm{~m} \mathrm{~s}^{-1}$, while dark pink surfaces denote reflectivity at $35 \mathrm{dBZ}$. Gray surfaces with low opacity in (b)-(d) represent reflectivity at $27 \mathrm{dBZ}$. Arrows in (b) indicate the locations of two high-wind funnels, $F_{1}$ (left) and $F_{2}$ (right). A black line at the bottom of $F_{2}$ in (c) outlines a portion of the touchdown area, whereas a cross in (d) indicates an estimated location of $F_{2}$ at the time assuming the horizontal translation speed is constant. The height of the lowest observation underneath the funnel $F_{2}$ was about $120 \mathrm{~m} \mathrm{AGL}$, and the highest observation was about $4400 \mathrm{~m}$ AGL in the funnel center in (c). The resolution in the figures is $150 \mathrm{~m}$ in the horizontal and $250 \mathrm{~m}$ in the vertical. 
AGL (Figs. 7b and 7c) by 2125 JST. Meanwhile, $\mathrm{F}_{2}$ continued downward at a speed of $4.3 \mathrm{~m} \mathrm{~s}^{-1}$, reaching the ground by 2125 JST (Fig. 7c). The distance and direction from the Doppler radar to the touchdown point of $F_{2}$ were $12.6 \mathrm{~km}$ and $256.3^{\circ}$ clockwise from north, respectively. The maximum horizontal dimensions of $F_{2}$ at 2125 JST were $5.3 \mathrm{~km}$ and $6.9 \mathrm{~km}$ in the north-south and eastwest directions, respectively, at an altitude of $400 \mathrm{~m}$ AGL. The steplike gap in the upper part of $\mathrm{F}_{2}$ is present because of limitations in radar beam elevation $\left(20^{\circ}\right)$. The horizontal translation speed and direction of $F_{1}\left(F_{2}\right)$ derived from Figs. $7 \mathrm{~b}$ and $7 \mathrm{c}$ are $19.4 \mathrm{~m} \mathrm{~s}^{-1}\left(17.3 \mathrm{~m} \mathrm{~s}^{-1}\right)$ and $20^{\circ}\left(22^{\circ}\right)$, respectively. These values are comparable with those of Higos at the time $\left(24 \mathrm{~m} \mathrm{~s}^{-1}, 23^{\circ}\right)$.

The translation speed of $F_{2}$ was likely reduced after reaching the ground, because the high winds from aloft associated with $\mathrm{F}_{2}$ did not reach the estimated point assuming the constant translation speed in $12 \mathrm{~min}$, but located behind it with extending above the MRI at 2137 JST (Fig. 7d). On the other hand, the relatively high reflectivity region (27 dBZ in Fig. 7d) corresponded to the thin-line echo was located ahead of $F_{2}$, suggesting the region of strong low-level winds overtook the funnels by 2137 JST. Indeed, the mean body depth of the region of strong low-level winds increased to $2 \mathrm{~km}$ by the time.

The mean radial speed and reflectivity averaged from the surface up to $2 \mathrm{~km}$ at the center of $F_{2}$ were $23.3 \mathrm{~m} \mathrm{~s}^{-1}$ and $2.7 \mathrm{dBZ}$ at $2125 \mathrm{JST}$, respectively (Fig. 7c). The fairly small mean reflectivity suggests that very light precipitation was occurring. This is consistent with the mostly rain-free region ahead of the eastern part of the thin-line echo in Fig. 5g. On the other hand, the radial wind speed at the center of $F_{2}$ increased from $22.8 \mathrm{~m} \mathrm{~s}^{-1}$ at $500 \mathrm{~m} \mathrm{AGL}$ to $31.0 \mathrm{~m} \mathrm{~s}^{-1}$ at $4000 \mathrm{~m} \mathrm{AGL}$. This increase of radial velocity with altitude is consistent with the funnel shape of $F_{2}$.

\subsection{The second thin-line echo}

About $30 \mathrm{~min}$ after the passage of the thin-line echo, a second thin-line echo appeared in the radar reflectivity field at 2218 JST, northwest of an outer rainband 2 of Higos, where the first thin-line echo had propagated (Fig. 8a). The length of the second thin-line echo with reflectivities more than $20 \mathrm{dBZ}$ was about $93 \mathrm{~km}$ and width of the segment that passed the MRI was about $5 \mathrm{~km}$. The length of the second thin-line was comparable to that of the
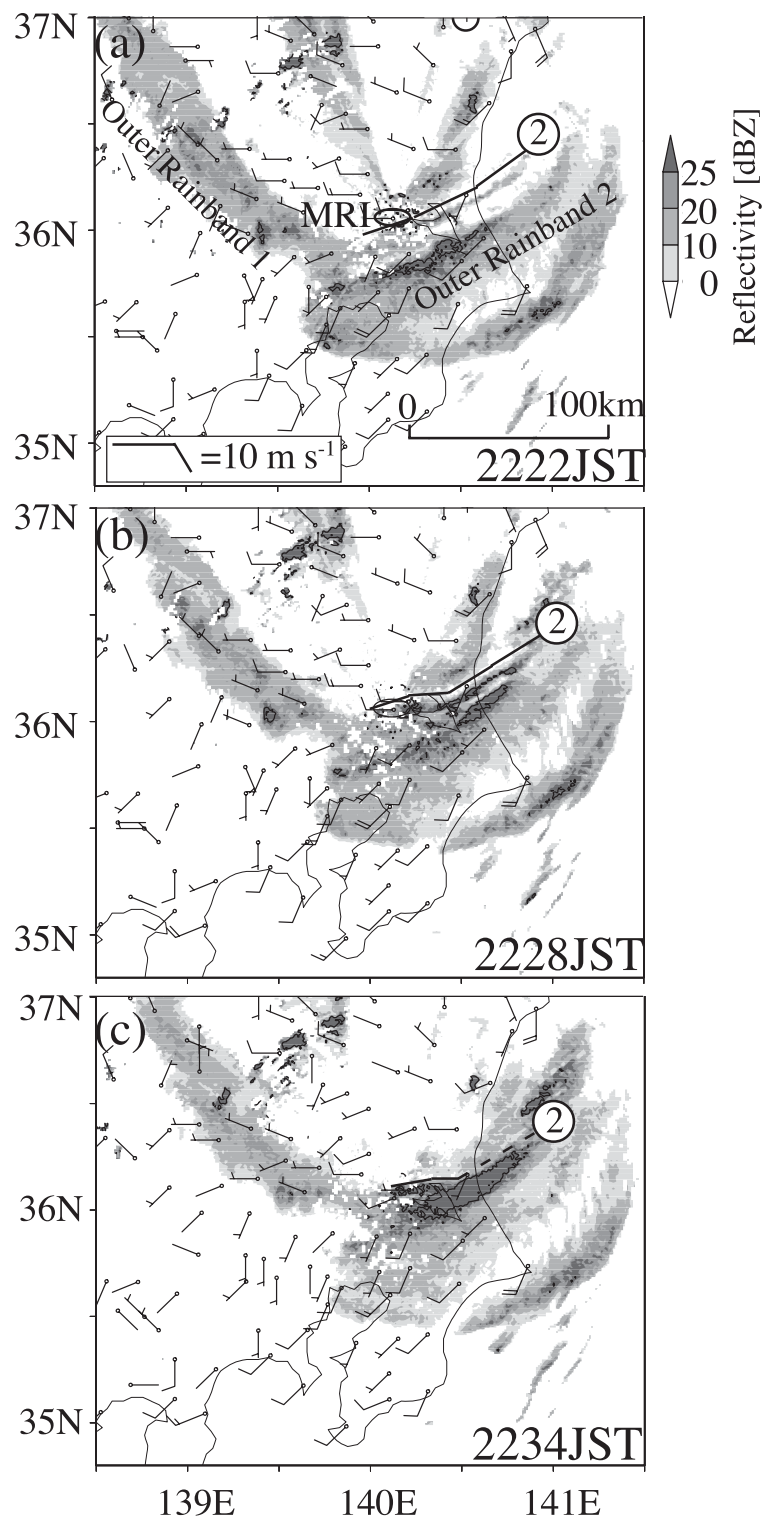

Fig. 8. Reflectivity at (a) 2222 JST, (b) 2228 JST, and (c) 2234 JST on 1 October. Surface winds at (a) $2230 \mathrm{JST}$, (b) $2230 \mathrm{JST}$, and (c) $2240 \mathrm{JST}$ are superimposed over the reflectivity. A full wind barb is $10 \mathrm{~m} \mathrm{~s}^{-1}$. The gray scale on the right represents reflectivity observed with the Doppler radar at a $0.3^{\circ}$ elevation angle. The thick contours represent reflectivity at $30 \mathrm{dBZ}$, while the thick line with a circled 2 in each image denotes the second thinline echo. A portion of the cross symbol in an open circle that denotes the typhoon center can be seen on the upper-right edge in (a). Open ovals in (a) and (b) denote the location of the MRI. 
outer rainband $2(\sim 140 \mathrm{~km})$ but width was much smaller than that of the outer rainband $(\sim 27 \mathrm{~km})$. The second thin-line echo then propagated northnorthwestward on the nearly rain-free inner side of the rainband (Fig. 8b). The second thin-line echo was likely produced by the rainband to the southeast, because it was parallel to the trailing outer rainband and the outer rainband was longer than the second thin-line echo (Fig. 8a). The second thin-line echo moved away from the parent rainband at a mean speed and direction of $16.2 \mathrm{~m} \mathrm{~s}^{-1}$ and $346^{\circ}$, respectively, passing the MRI site at about 2230 JST (Figs. $8 \mathrm{~b}$ and $8 \mathrm{c}$ ). These values are determined from the observations between 2217 and 2235 JST as derived for the first thin-line echo. Winds gusted to $17.6 \mathrm{~m} \mathrm{~s}^{-1}$ at the MRI site just after the second thin-line echo arrived. The propagation speed of Higos $\left(\sim 24 \mathrm{~m} \mathrm{~s}^{-1}\right)$ exceeded that of the second thin-line echo, and after intensifying ahead of the parent rainband (Fig. 8b), the second thin-line echo was overtaken by the trailing parent rainband at 2241 JST (not shown).

Both thin-line echoes were accompanied by gusty winds, so horizontal convergence likely occurred between gusty winds behind the thin-line echoes and environmental winds ahead. The next section focuses on surface measurements and the vertical structure of the gusty winds behind the thin-line echoes to elucidate characteristics including horizontal convergent flows above the MRI site.

\section{Vertical structure of the gusty winds associated with the thin-line echoes}

\subsection{Depressed temperature periods}

Time series of surface wind speed, temperature, and pressure recorded at the $\mathrm{AO}$ characterize the cold airflows behind the thin-line echoes (Fig. 9). The general decrease in pressure before 2105 JST and the subsequent increase reflect the passage of the typhoon. The wind speed was weakest around 2115 JST, when the typhoon center was closest $(\sim 3 \mathrm{~km})$ to the AO. A small temperature depression $\left(\sim 0.4^{\circ} \mathrm{C}\right)$ occurred as the typhoon center passed. This slight cooling may reflect a cold temperature anomaly near the typhoon center at low altitudes (e.g., Hawkins and Imbembo 1976; Halverson et al. 2006). Larger temperature depressions occurred about $35 \mathrm{~min}$ after the typhoon passed.

Two periods of depressed temperatures can be defined from the time series of temperature. The first period, $\mathrm{P}_{1}$, from $2150 \mathrm{JST}$ to $2230 \mathrm{JST}$, is associated with cold airflow behind the first thin-line

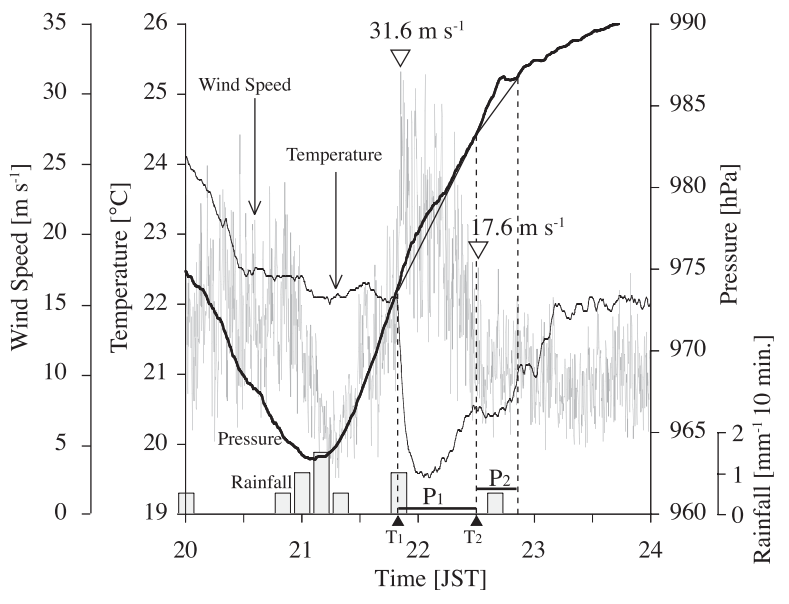

Fig. 9. Time series of the surface wind speed (light gray), temperature (fine line), pressure (thick line), and rainfall amount (histogram) recorded at the AO from 2000 JST to 2400 JST on 1 October 2002. Wind speed values are 10-s means and are plotted at the end of the time interval. Pressure and temperature values are 1-min running means, whereas rainfall values are 10min amount, plotted at the middle of the time interval. Thick lines at the bottom denote the two periods with depressed temperatures $\left(\mathrm{P}_{1}: 2150-2230 \mathrm{JST} ; \mathrm{P}_{2}\right.$ : 22302250 JST), which are defined by dashed vertical lines. Thin lines connect pressure values at both ends of the depressed temperature periods to highlight the pressure deviations. Downward pointing triangles indicate the maximum wind speeds in $\mathrm{P}_{1}$ and $\mathrm{P}_{2}$, whereas upward pointing triangles on the bottom indicate arrival times of the first $\left(T_{1}\right)$ and second $\left(T_{2}\right)$ thin-line echoes at 2150 JST and 2230 JST, respectively.

echo (Figs. 5c and 5d), and the first temperature drop corresponds to the arrival of the first thin-line echo at the MRI (Fig. 5h). The second period, $\mathrm{P}_{2}$, from 2230 JST to $2250 \mathrm{JST}$, is associated with the cold air behind the second thin-line echo. Wind gusts were observed in both temperature depressed periods. These characteristics in temperature and wind speed were also observed at the top of the tower, meaning that the depth of the cold airflows exceeded $200 \mathrm{~m}$. The fastest wind gust in the first period was $31.6 \mathrm{~m} \mathrm{~s}^{-1}$ at $2151 \mathrm{JST}$, and other big gusts followed in the same period. The fastest gust in the second period was $17.6 \mathrm{~m} \mathrm{~s}^{-1}$ at $2231 \mathrm{JST}$. 


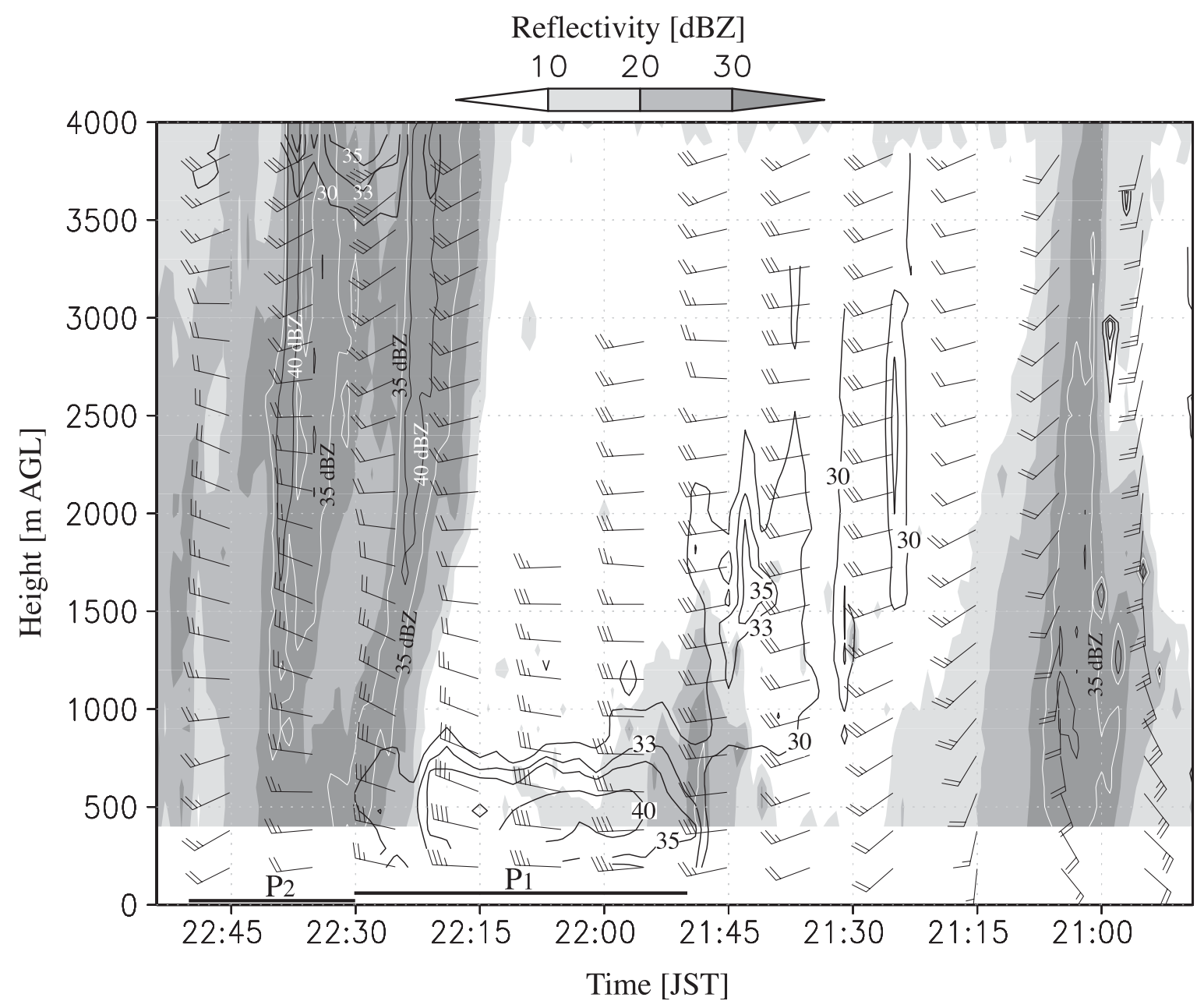

Fig. 10. Time-height cross section of wind profiler observations showing horizontal wind vectors and reflectivity from 2050 JST to 2255 JST on 1 October 2002. Time progresses from right to left and a full wind barb is $10 \mathrm{~m} \mathrm{~s}^{-1}$. The gray scale with thin contours represents reflectivity and thick contours are isotachs equal to or greater than $30 \mathrm{~m} \mathrm{~s}^{-1}$, with a contour interval of $5 \mathrm{~m} \mathrm{~s}^{-1}$. Contours of $33 \mathrm{~m} \mathrm{~s}^{-1}$ are also plotted for ease of viewing. Wind speeds are 2-min means and are plotted at the middle of the averaging intervals. Wind barbs are 10-min means and are plotted in the middle of the averaging intervals and at every other range gate up to about $4 \mathrm{~km}$ for clarity of viewing. Gaps in the wind speed contours occur where low quality profiler data were rejected. Reflectivity values are 1-min means, plotted at the end of the minute. The thick lines at the bottom indicate the two periods with depressed temperatures defined in Fig. 9.

Extreme surface winds can be much larger than these values because observed wind speeds are 10-s means. Pressure rises were present in both periods, suggesting that a relatively cold dense air mass passed the MRI site during each period. Wind profiler observations accurately captured some characteristics of the gusty winds associated with the cold airflow.

\subsection{Wind vector and reflectivity profiles}

Figure 10 shows time-height cross sections of horizontal wind vectors and reflectivities observed with the MRI wind profiler. Time increases from right to left so the westerly winds associated with the first cold airflow appear to move toward the first thin-line echo propagated east-northeastward. Thick isotachs represent 2-min mean horizontal 
wind speeds exceeding $30 \mathrm{~m} \mathrm{~s}^{-1}$. Reflectivity data at or lower than the second gate $(300 \mathrm{~m})$ were not included in the figure because reflectivity determined with the profiler at these altitudes is unreliable due to a nonlinear receiver response that reduces the measuring signal power, especially in heavy rain as noted by Ralph (1995). Wind vectors derived from the wind profiler at these lower altitudes can be trusted because the receiver did not become completely saturated in the heavy rain. In fact, wind vectors observed with the profiler are consistent with tower measurements as shown below. An unfolding algorithm (Miller et al. 1994) was applied at all gates because wind speeds even at the lowest gate were high enough to be aliased.

The large reflectivities at 2105 JST and 2150 JST correspond to heavy precipitation in region $\mathrm{A}_{2}$ (Fig. 5f) and the first thin-line echo (Fig. 5h), respectively. Similarly, large reflectivities at 2225 JST and 2240 JST correspond to the second thin-line echo and the outer rainband 2 in Figs. $8 \mathrm{~b}$ and 8c, respectively. Strong winds occurred just behind the first thin-line echo at altitudes below $1000 \mathrm{~m}$; maximum winds behind the first thin-line echo exceeded $44 \mathrm{~m} \mathrm{~s}^{-1}$ at about $500 \mathrm{~m}$. The strong winds behind the first thin-line echo were connected with another region of strong winds aloft observed around 2137 JST ahead of the first thin-line echo. This region could have been part of the funnel of high wind observed by the Doppler radar at this time (Fig. 7d). Wind shifts that heralded the passage of the first thin-line echo were not distinct, perhaps because the first thin-line echo traveled east-northeast with the mean flow of the typhoon, and little difference in wind direction existed across the first thinline echo, as described in Section 3. The strong low-level winds terminated with the arrival of the outer rainband around 2230 JST, which is consistent with the Doppler radar observations (Figs. $6 \mathrm{~g}$ and $6 \mathrm{~h}$ ).

The strongest winds at low altitudes in the second period $\left(\mathrm{P}_{2}\right)$ were not distinct. Gusts at the arrival of the second thin-line echo were not as strong as those in the first period (Fig. 9), and characteristic features of the second thin-line echo in wind speed may have been smeared out by strong winds caused by the typhoon in the figure. Since strong winds due to the typhoon dominated in the tangential direction, an analysis of the horizontal wind speed in the radial direction could mitigate the effects of the typhoon because the second echo propagated toward the typhoon center.

\subsection{Horizontal wind speed and convergence in the cold airflow directions}

Figure 11 shows time-height cross sections of horizontal wind speed and convergence and wind vectors. Observations up to $200 \mathrm{~m}$ are from the tower; higher observations are from the wind profiler. No smoothing was performed between the two observations; because of the typhoon, the averaged wind speed was sufficiently large $\left(>20 \mathrm{~m} \mathrm{~s}^{-1}\right)$ to compensate for spatial differences between the two instruments $(\sim 300 \mathrm{~m})$. Wind vectors observed with the profiler are consistent with tower measurements. A time-space conversion based on the speed of each thin-line echo was used to compute convergence. The horizontal wind speed is for the wind component normal to the second thin-line echo $\left(346^{\circ}\right.$, Fig. 11b). In contrast, the horizontal wind speed for the first thin-line echo is the wind component not in the propagation direction of the echo $\left(71^{\circ}\right)$ but in the direction $87^{\circ}$, where the convergence at altitudes of less than $600 \mathrm{~m}$ was the largest (Fig. 11a). This direction is consistent with the wind direction just behind the first thin-line echo (Fig. $5 \mathrm{~h}$ ). This method was chosen because neither the propagation direction of the thin-line echo nor the direction perpendicular to the thin-line echo represented the wind direction in the cold airflow just behind the first thin-line echo as mentioned in Section 3.

This figure shows that each temperature depression period $\left(\mathrm{P}_{1}\right.$ and $\left.\mathrm{P}_{2}\right)$ was associated with strong horizontal convergence near the surface. The first region of convergence occurred at altitudes less than $800 \mathrm{~m}$ between 2147 JST and 2149 JST just ahead of the strong winds and corresponds to the first thin-line echo (Fig. 10). The maximum intensity in the first region of convergence in the direction $87^{\circ}$ was $3.2 \times 10^{-3} \mathrm{~s}^{-1}$ at $400 \mathrm{~m}$ AGL at 2147 JST. The strong winds $\left(>40 \mathrm{~m} \mathrm{~s}^{-1}\right)$ behind the first thin-line echo at altitudes below $1000 \mathrm{~m}$ well exceeded the propagation speed of the first thin-line echo $\left(19.5 \mathrm{~m} \mathrm{~s}^{-1}\right)$, except near the surface. The 33 and $35 \mathrm{~m} \mathrm{~s}^{-1}$ isotaches depict the elevated nose (at 2148 JST) and the head-like structures (at 2153 JST). These features will be discussed below.

In contrast, the second temperature depression period $\left(\mathrm{P}_{2}\right)$ was characterized by convergence in the direction normal to the second thin-line echo during the first half and by divergence in the second half. The maximum convergence before 2240 JST was $3.6 \times 10^{-3} \mathrm{~s}^{-1}$ at $600 \mathrm{~m}$ AGL at $2233 \mathrm{JST}$. Divergence above $200 \mathrm{~m}$ ended as the second period 


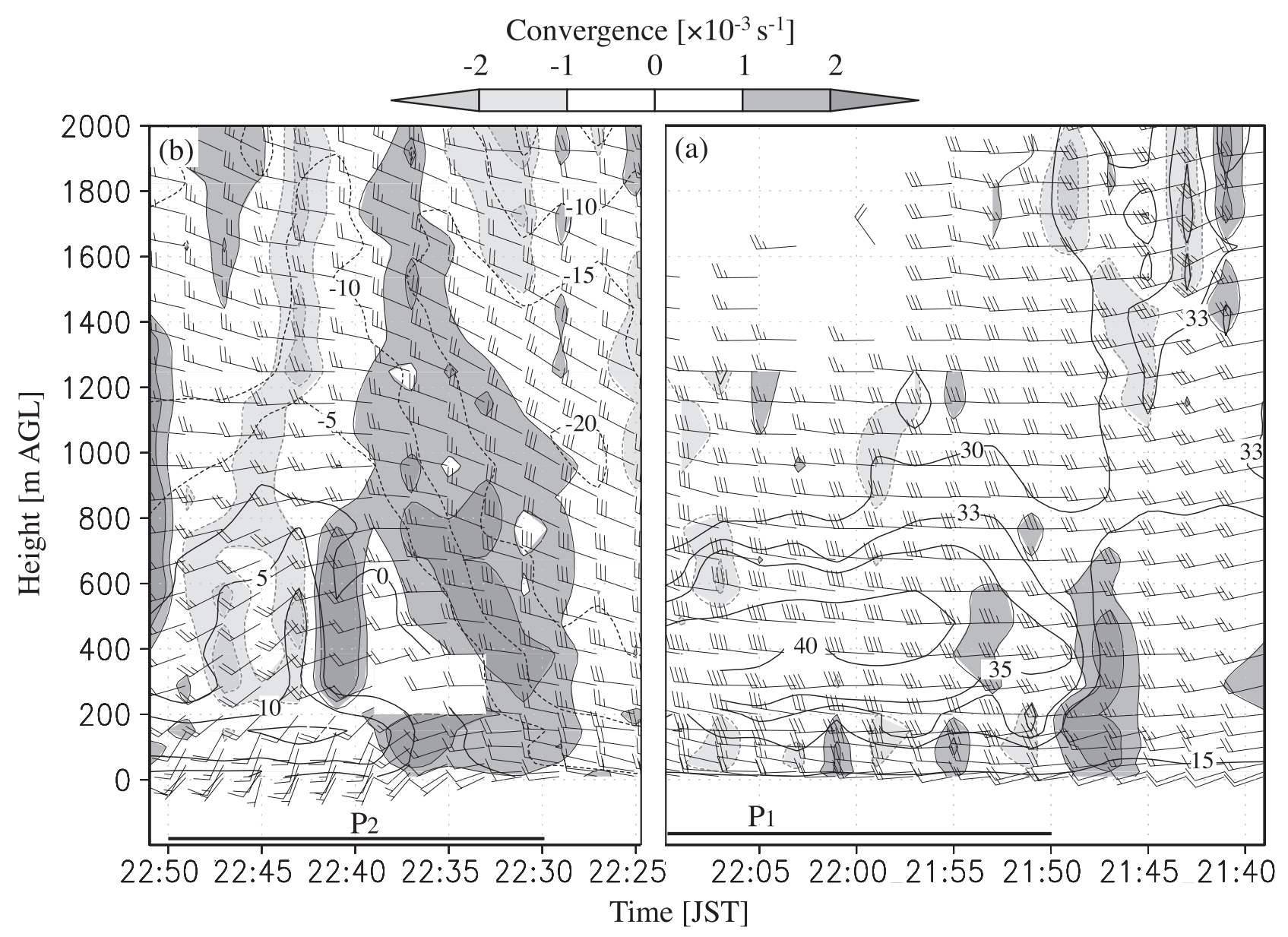

Fig. 11. Time-height cross section of horizontal convergence in the cold airflow direction behind the thinline echo and wind vectors derived from wind profiler observations (a: right) between 2139 JST and $2210 \mathrm{JST}$, and (b) between $2225 \mathrm{JST}$ and $2251 \mathrm{JST}$ on 1 October 2002. Time progresses from right to left and a full wind barb is $10 \mathrm{~m} \mathrm{~s}^{-1}$. The gray scale with solid (dashed) contours represents convergence (divergence). Thick black contours are isotachs of wind speed in the direction $87^{\circ}$ equal to or greater than $30 \mathrm{~m} \mathrm{~s}^{-1}$ with a contour interval of $5 \mathrm{~m} \mathrm{~s}^{-1}$ along with contours of $15 \mathrm{~m} \mathrm{~s}^{-1}$ and $33 \mathrm{~m} \mathrm{~s}^{-1}$ in (a), and wind speed in the direction $346^{\circ}$ with positive (negative) values shown by solid (dashed) lines with a contour interval of $5 \mathrm{~m} \mathrm{~s}^{-1}$ in (b). All data are 2-min means and are plotted at the middle of the averaging intervals. Data up to $200 \mathrm{~m}$ altitude are from the tower, and higher observations are derived from the wind profiler. The thick lines at the bottom indicate the two periods with depressed temperatures defined in Fig. 9.

$\left(\mathrm{P}_{2}\right)$ ended. Note that winds turned slightly counterclockwise in the first half of the second period and clockwise in the second half of the period at altitudes above $1000 \mathrm{~m}$. This means southerly wind component, which is consistent with the propagation direction of the second thin-line echo, gradually increased and then decreased in the second period. This point is discussed in the following section.
On the other hand, south-southwest winds beginning at 2237 JST below $200 \mathrm{~m}$ were not attributable to the second thin-line echo because these winds began in the middle of the second period $\left(\mathrm{P}_{2}\right)$ and persisted after the end of the period. The south-southwest winds near the surface behind the outer rainband were also present in surface measurements (Fig. 8c). Strong convergence at 2242 JST at altitudes between 200 and $800 \mathrm{~m}$ might 


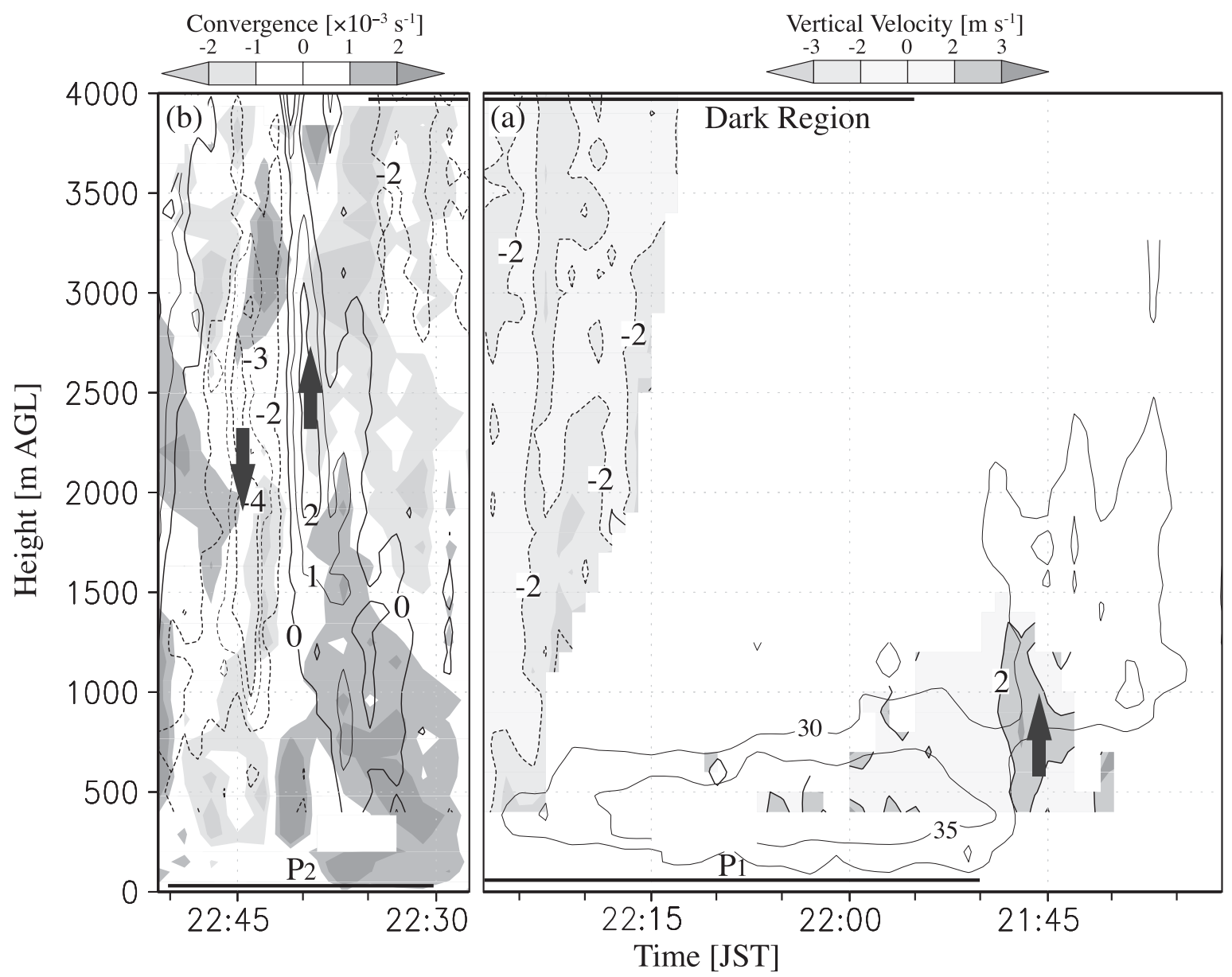

Fig. 12. Time-height cross section of vertical motion and horizontal convergence derived from the wind profiler between 2133 JST and 2251 JST on 1 October 2002. Time progresses from right to left. Thick contours represent vertical airflow within $\pm 4 \mathrm{~m} \mathrm{~s}^{-1}$ with a contour interval of $1 \mathrm{~m} \mathrm{~s}^{-1}$ for ease of viewing. Upward (downward) airflows are positive (negative) values shown by solid (dashed) lines. The gray scale in (a) represents vertical flow, whereas that in (b) represents convergence as in Fig. 11. Arrows denote the direction of the vertical airflow. The wind speed in the front propagation direction measured with the profiler and the tower is also plotted with thin contours to represent the low-level high winds in (a). The thick lines at the bottom indicate the two periods with depressed temperatures defined in Fig. 9, and the lines at the top represent the passage duration of the dark region estimated from Figs. 5, 8 and 10.

reflect contamination from these winds, because the strong convergence is inconsistent with data nearby in time and vertical space. Nevertheless, this analysis demonstrates that both thin-line echoes were accompanied by horizontal convergent flows, and such convergent flows are expected to induce updrafts.

\subsection{Vertical airflows}

An essential measurement needed to analyze gust fronts is the vertical component of wind. Figure 12 shows time-height cross sections of the vertical component of wind derived from the wind profiler. Time runs from right to left as in Figs. 10 and 11, and the gray scale at the top of Fig. 12a (right) and contours in Fig. 12b are for the vertical component of wind estimated from the profiler; positive values represent updrafts. Vertical velocities were derived from reflectivities and hydrometeor falling velocities measured with the profiler as described in Appendix A. Only reflectivity data equal to or greater than $15 \mathrm{dBZ}$ were used because this method 
is meant for reflectivity exceeding $10 \mathrm{~mm}^{6} \mathrm{~m}^{-3}$ $(=10 \mathrm{dBZ})$. Data below $400 \mathrm{~m}$ were not used to avoid the error caused by nonlinear receiver response effects. Gaps in the figure are regions of low reflectivity.

The profiler captured the strong upward air motion $\left(\sim 3 \mathrm{~m} \mathrm{~s}^{-1}\right)$ at the passage of the first thin-line echo. This motion corresponds to convergent flow that occurred just ahead of the first temperature depression period $\left(\mathbf{P}_{1}\right)$ in Fig. 11. The profiler also observed weak downward motions $\left(\sim 2 \mathrm{~m} \mathrm{~s}^{-1}\right)$ aloft after $2215 \mathrm{JST}$, one of which reached $400 \mathrm{~m}$ at 2225 JST. The weak down motions continued to the end of the first temperature depression period $\left(\mathrm{P}_{1}\right)$, when the second thin-line echo and outer rainband arrived, suggesting the existence of subsidence in the dark region (Fig. 5g).

In contrast, a strong up-down couplet occurred during the second period $\left(\mathrm{P}_{2}\right)$ in Fig. 12b. In this case, the entire vertical airflow was captured because of high reflectivities associated with heavy rain from the second thin-line echo and from the outer rainband (Fig. 10). Upward motions began below $1800 \mathrm{~m}$ at $2233 \mathrm{JST}$, a few minutes after the beginning of the second temperature depression period $\left(\mathrm{P}_{2}\right)$. The upward motions then intensified and extended in altitude with time. The maximum upward motion was $2.5 \mathrm{~m} \mathrm{~s}^{-1}$ at 2240 JST at the altitude of $2500 \mathrm{~m}$. This distinct upward motion was followed and replaced by downward motions at about 2242 JST, in the middle of the second temperature depression period $\left(\mathrm{P}_{2}\right)$. The downward motions ended as the second period $\left(\mathrm{P}_{2}\right)$ ended. This system extended up to $3.5 \mathrm{~km}$, with maximum speeds exceeding $\pm 2.5 \mathrm{~m} \mathrm{~s}^{-1}$ at $2-2.5 \mathrm{~km}$. These are robust measurements of vertical air motions that exceed the accuracy of the method $\left( \pm 1 \mathrm{~m} \mathrm{~s}^{-1}\right)$. Strong upward (downward) motions occurred at the altitudes between low-level $(0-2 \mathrm{~km})$ convergence (divergence) and divergence (convergence) aloft. The strong up-down couplet not only occurred in the second thin-line echo but continued in the trailing outer rainband 2 (Figs. 10 and 12). These features are discussed in the following section.

The Doppler radar and wind profiler observations reveal characteristics of the thin-line echoes and the atmospheric conditions surrounding them. However, the causes of the thin-line echoes have not yet been determined, even though such features are often observed with gust fronts. The next section explores the cause of the two thin-line echoes.

\section{Discussion}

Within the typhoon, Doppler radar observed the appearance of two thin-line echoes that passed the MRI. Both thin-line echoes were accompanied by gusty winds. Because gust fronts are often associated with thin-line echoes in radar reflectivity (e.g., Wilson and Schreiber 1986; Friedrich et al. 2005), the ones in this study may have been due to a gust front. Of course, gust fronts are not the only cause of thin-line echoes in radar reflectivity fields. However, both thin-line echoes were accompanied by other characteristics that are often observed with gust fronts: updraft along the front (e.g., Martner 1997; Knupp 2006), a cold air pool just behind the front (e.g., Wakimoto 1982; Mueller and Carbone 1987), and horizontal convergence at the front (e.g., Charba 1974; Gilmore and Wicker 1998). In addition, maximum convergence associated with the first (second) thin-line echo as estimated from 2 -min mean wind profiler data was $3.2 \times 10^{-3} \mathrm{~s}^{-1}$ $\left(3.6 \times 10^{-3} \mathrm{~s}^{-1}\right)$ in the component of the wind direction just behind the echo (in the propagation direction of the echo). These values agree with results from Friedrich et al. (2005), who found that average maximum convergence ranged from $1.0 \times 10^{-3}$ to $4.7 \times 10^{-3} \mathrm{~s}^{-1}$ in the direction normal to the thin-line echo associated with a gust front. Moreover, wind profiler observations suggest that the cold pool behind the second thin-line echo was associated first with updrafts and then with downdrafts. This observation agrees with characteristics of cold outflow from numerically simulated thunderstorms by Droegemeier and Wilhelmson (1987, and their Fig. 10c). They also showed that this updown couplet is associated with the horizontallyoriented circulation centered immediately behind the outflow head, which is set up by the advancing gust front. These facts also suggest that both thinlines were associated with gust fronts.

The characteristics enumerated above, however, do not prove that the two thin-line echoes were due to gust fronts, because other boundaries associated with drylines (e.g., Weiss and Bluestein 2002; Xue and Martin 2006), cold fronts (Neiman and Wakimoto 1999; Wakimoto and Bosart 2000) and gravity waves (e.g., Koch and Clark 1999; Knupp 2006) sometimes show similar features. Therefore, the inherent features of a gust front must be shown to confirm that the two thin-line echoes in the present study were associated with gust fronts.

The present study defines a gust front as a 
boundary separating cold air outflow from the displaced warm air, as proposed by Goff (1976). Many studies (e.g., Charba 1974; Goff 1976; Wakimoto 1982; Droegemeier and Wilhelmson 1987) have examined the motion of gust fronts, and determined that storm outflow behaves more or less as a gravity current (Corfidi 2003). Thus, the finding of characteristics unique to gravity currents in the cold airflows associated with the two thin-line echoes examined in this study is additional evidence that they were gust fronts.

A prominent and ubiquitous feature of a gravity current is that the flow above a shallow friction layer immediately behind the leading edge is toward the leading edge in a frame of reference moving with the leading edge (Smith and Reeder 1988). This so-called feeder flow extends back to the source of cold air for a steady gravity current in the laboratory (Simpson and Britter 1979). Accordingly, the existence and extent of any such feeder flow in observations of cold airflows is an important consideration in assessing the relevance of gravity current theory. In the shallow friction layer, however, the lowest streamlines in the flow relative to the head are toward the rear (Simpson 1997). This draginduced surface layer flow away from the front is called cold air backflow (Goff 1976). To investigate the cause of the two thin-line echoes, we next explore these features in the cold airflows behind.

\subsection{The first thin-line echo \\ a. Gust front features in the first cold outflow}

The first thin-line echo was always at the leading edges of both the cold airflow at the surface (Figs. $5 \mathrm{c}, 5 \mathrm{~d}, 5 \mathrm{~g}$, and $5 \mathrm{~h}$ ) and the region of strong lowlevel winds (Figs. 6f and 7b). Temperatures decreased up to $550 \mathrm{~m}$ MSL from the surface after the thin line passed (Figs. 3 and 9), suggesting that the strong low-level winds were accompanied by cold air. As the thin-line echo propagated northeastward, the leading edge of the cold airflow moved with it but the origin of the cold airflow remained under the region of high winds aloft, where the strong low-level winds were generated (Fig. 6f), until the outer rainband 1 reached the area (Figs. $6 \mathrm{~g}$ and $6 \mathrm{~h}$ ). These features were also seen in the analysis with a radial wind speed of $25 \mathrm{~m} \mathrm{~s}^{-1}$ (not shown). The wind speed in the cold airflow could be much larger since the radial wind speed observed by the Doppler radar is equal to or less than the actual horizontal wind speed. This means that the wind speed in the cold airflow in the propagation direction of the first thin-line echo well exceeded the propagation speed of the first thin-line echo $\left(19.5 \mathrm{~m} \mathrm{~s}^{-1}\right)$ because the wind speed in the propagation direction was likely little different $(\sim 4 \%)$ from the actual wind speed since the propagation direction $\left(71^{\circ}\right)$ nearly paralleled to the wind direction $\left(\sim 87^{\circ}\right)$ just behind the thin-line echo. Indeed, the profiler observed (Fig. 10) that strong low-level high winds $\left(>30 \mathrm{~m} \mathrm{~s}^{-1}\right)$ continued to the end of the first period $\left(\mathrm{P}_{1}\right)$. These facts show the presence of a feeder flow extending all the way to the cold air source.

On the contrary, both cold air backflow in the surface layer and a so-called nose structure are obscure in the Doppler radar observations (Figs. 7a and $7 \mathrm{~b}$ ). This could be because the spatial and temporal resolutions of the Doppler radar observations were too coarse to capture these detailed features of the cold airflow. Fortunately, wind profiler and tower observations captured these features.

Figure 11a shows that the strong winds just behind the first thin-line echo exceeded the propagation speed of the first thin-line echo at altitudes below $1000 \mathrm{~m}$, except close to the surface. Wind speeds at altitudes below $25 \mathrm{~m}$ were less than $15 \mathrm{~m} \mathrm{~s}^{-1}$ (Fig. 11a), which is less than the propagation speed of the first thin-line echo, suggesting the presence of a cold air backflow. Moreover, the contours of horizontal wind speed depict an elevated nose and head-like structures near the surface.

Additional support for our hypothesis is provided from the Froude number $(F r)$ for the first thin-line echo. Appropriate values of $\mathrm{Fr}$ for atmospheric gravity currents appear to lie in the range of $0.7-1.1$ when the mean depth of the cold air is considered (Wakimoto 1982; Smith and Reeder 1988). The value of $\mathrm{Fr}$ for the cold airflow associated with the first thin-line echo in this study is 0.76 (see Appendix B), which is within the range.

Since the cold airflow associated with the first thin-line had features unique to a gravity current and had an appropriate value of $F r$, we conclude that the first thin-line echo was due to a gust front. The main source of cold outflow behind a thunderstorm gust front is the cold thunderstorm downdraft (Wakimoto 1982). What generated the downdrafts in the present study?

\section{b. Downdrafts}

Doppler radar observation showed that the first thin-line echo was modified from a convective storm that was formed by merging of two convec- 
tive storms (Figs. 4, 5 and 6). Studies have shown that merged convective systems were capable of producing more rain and generating stronger downdrafts than isolated systems through a dynamic invigoration of the storm (e.g., Westcott 1984; Westcott 1994). The existence of any such strong downdraft from the merged storm could not be verified from the analysis in the present study. However, even if this kind of downdrafts occurred, the downdrafts cannot be related to the cold lowlevel high winds behind the first thin-line echo, because the low-level high winds (Fig. 6e) extended far beyond the region where storms $\mathrm{A}_{1}$ and $\mathrm{B}$ or the merged storm $\mathrm{A}_{3}$ were located as noted earlier (Figs. $6 \mathrm{a}$ and $6 \mathrm{~b}$ ). Indeed, the merged system was modified into the thin-line echo after the low-level high winds reached it (Figs. 6d and 6f). Moreover, the area of the cold air mass associated with the lowlevel high winds expanded with time as it moved eastward despite the lack of convective storms that supplies cold air from behind (Figs. 5b, 5c, 5f and $5 \mathrm{~g}$ ). Another interpretation is, therefore, needed.

The vertical velocity field derived from the wind profiler indicates that weak subsidence $\left(\sim 2 \mathrm{~m} \mathrm{~s}^{-1}\right)$ occurred in the dark region (Fig. 12). Ahrens (2003) suggests the existence of subsidence between spiral rainbands of hurricanes. The subsidence compensates for updrafts near the hurricane center and/or in the rainbands. More recently, Curry and Biggerstaff (2005) analyzed Hurricane Isabel with a dual Doppler radar network. Their results suggest that the mesoscale $(\geq 2 \mathrm{~km})$ deep subsidence zones exist in the weak radar-reflectivity regions in between spiral rainbands of the hurricane. They also showed that the magnitudes of the subsidence were typically less than $3 \mathrm{~m} \mathrm{~s}^{-1}$. These results agree well with our observations. However, the descent speed of the funnel $\left(4.3 \mathrm{~m} \mathrm{~s}^{-1}\right)$ with a diameter of less than $1 \mathrm{~km}$ (Fig. 7) was much larger than the mesoscale subsidence, suggesting the presence of microscale $(<2 \mathrm{~km}$; Orlanski 1975) downdrafts in the subsidence zone.

Doppler radar observations suggest that the microscale downdrafts to the surface occurred only at specific times in discrete zones and were not observed elsewhere in the weak reflectivity region (the dark region). This means downdrafts took place in the region where kinematic and/or thermodynamic factors were most favorable for development; this is because maintenance of the convective downdraft balances the competing forces of cooling due to phase changes of condensate (including evapora- tion) versus warming due to dry adiabatic compression (Wakimoto 2003). The melting layer in the high-wind region aloft and the relatively dry layer underneath (Fig. 3) might have enhanced phase changes of condensate.

Since convective downdrafts are associated with cooling due to phase changes of hydrometeors, it supplies cold air to the surface. Indeed, the expansion of the cold air region with time was observed in a weak rain region within the dark region where the relatively dry layer aloft was observed, suggesting cold air was supplied through the evaporation of rain. Moreover, the downdrafts in $\mathrm{F}_{2}$ (Fig. 7c) likely supplied cold air to the surface and expanded the cold air region to the west of the MRI behind the first thin-line echo.

The expansion of the cold air region, however, cannot be the cause of the low-level high winds. On the other hand, the downdrafts associated with the descent of $F_{2}$ might be too small to produce the gust front by itself in the present study. Indeed, results from Knupp (1987) suggest that downdrafts stronger than $10 \mathrm{~m} \mathrm{~s}^{-1}$ are necessary to generate surface winds exceeding $20 \mathrm{~m} \mathrm{~s}^{-1}$. Therefore, another additional mechanism that supports the generation of the low-level high winds is required.

\section{c. Momentum transfer}

Kuchera and Parker (2006) and Corfidi (2003) suggested that downdrafts can transfer highmomentum air to the surface from aloft and generate damaging winds including gust fronts. Doppler radar observations show that strong low-level winds behind the gust front were produced (Figs. 6b-d) and enhanced (Figs. 6e and 6f) after high winds from aloft reached to the ground. These high winds from aloft were not observed before the onset of the strong low-level winds (Figs. 6a and 6b). Note that the sparse low-level high winds in Figs. $6 \mathrm{a}$ and $6 \mathrm{~b}$ were located in the region where the low-level high winds expanded in the subsequent radar velocity field (Fig. 6f), suggesting that the sparse distributions of low-level high winds in the figures were not due to limitations in radar beam elevation $\left(0.6^{\circ}\right)$ but meant the low-level high winds did not occur at the time yet since the observations were made in the region of precipitation echoes (Figs. $4 \mathrm{~b}$ and $4 \mathrm{c}$ ), which was essential for the Doppler radar observations. In addition, the mean body depth of the region of strong low-level winds increased after the region of strong low-level winds overtook the funnels (Figs. 7b-d). Thus, it is likely that they indicate 
transport of large momentum from aloft to lower levels, enhancing near-surface wind speeds.

This hypothesis is also supported by other analyses below. As noted earlier, Doppler radar observations showed that filaments and funnels with high winds occurred only at specific time in discrete zones (Figs. 6 and 7). This means that vertical momentum transport supplies strong low-level winds intermittently, not continuously. Intermittent momentum supply is consistent with the frequent gusty winds that occurred in the first period ( $P_{1}$ in Fig. 9). On the other hand, if momentum transport occurred from aloft to the surface, momentum should be conserved in the vertical direction. To investigate the vertical conservation of momentum in the funnel $\mathrm{F}_{2}$, we define horizontal momentum per unit volume $P$ as,

$$
P=\rho \frac{-V_{r}+w \cdot \sin \theta}{\cos \theta},
$$

where $\rho$ is atmospheric density at given altitude, $\mathrm{Vr}$ is radial velocity measured with the Doppler radar (negative toward the radar), $w$ is the vertical component in $\mathrm{F}_{2}$ (positive upward), and $\theta$ is the elevation angle of the Doppler radar. The radiosonde observation at 2209 JST showed that the atmospheric density decreased with height almost linearly from $1.156 \mathrm{~kg} \mathrm{~m}^{-3}$ at the surface to $0.761 \mathrm{~kg} \mathrm{~m}^{-3}$ at $4000 \mathrm{~m} \mathrm{AGL}$. The mean and the standard deviation of the horizontal momentum per unit volume $P$ for altitudes from $500 \mathrm{~m}$ AGL and $4000 \mathrm{~m} \mathrm{AGL}$ were $24.1 \mathrm{~kg} \mathrm{~m}^{-2} \mathrm{~s}^{-1}$ and $0.4 \mathrm{~kg} \mathrm{~m}^{-2} \mathrm{~s}^{-1}$, respectively. In the derivation, vertical velocity $w$ is assumed to be $-4.3 \mathrm{~m} \mathrm{~s}^{-1}$ at all heights. If vertical component was negligible $\left(w=0 \mathrm{~m} \mathrm{~s}^{-1}\right)$ at all heights, these values changed to $24.6 \mathrm{~kg} \mathrm{~m}^{-2} \mathrm{~s}^{-1}$ and $0.4 \mathrm{~kg} \mathrm{~m}^{-2} \mathrm{~s}^{-1}$, respectively. In both cases, the standard deviations were surprisingly small $(\sim 1.8 \%)$ with respect to the means despite the large decrease of the atmospheric density with altitude $(\sim 66 \%)$, meaning momentum was vertically conserved.

From those observational results, we conclude that the gust front behind the first thin-line echo was produced and maintained by relatively strong downdrafts and large momentum transport by the downdrafts from aloft in a subsidence zone of the typhoon.

\subsection{The second thin-line echo}

The second thin-line echo was likely produced by the rainband 2 , because it was parallel to the trail- ing outer rainband 2, and moved away from it as noted in Section 3. This suggests that the second echo has not been due to a dry-line or a cold front but may have been associated with a gust front or an internal gravity wave that evolved from the gust front. Wind profiler observations clearly show a strong up-down couplet within the temperature depression period behind the second thin-line echo $\left(\mathrm{P}_{2}\right.$ in Fig. 12). Up-down couplet is often observed immediately behind the head of a gust front that propagates horizontally away from the source of cold air to which the feeder flow extends. However, feeder flow did not exist at this stage because maximum upward and downward motions occurred in the outer rainband 2, which should have been the source of cold air. This means that the cold airflow associated with the second thin-line did not have features unique to a gravity current. Thus, the second thinline echo was not associated with a gust front and may have been due to an internal gravity wave.

The most commonly documented scenario for gravity wave formation involves a gravity current propagating into a region of strong static stability, such as a nocturnal inversion (e.g., Kingsmill and Crook 2003; Adachi et al. 2004b). Recall that the second thin-line echo was generated ahead of outer rainband 2, where the first thin-line echo propagated (Figs. 5g and 8a). Cold airflow followed the first thin-line echo, so a stable layer should have existed ahead of the outer rainband 2. Indeed, a radiosonde launched behind the gust front at 2209 JST (Fig. 3) observed colder air below $550 \mathrm{~m} \mathrm{MSL}$ and two inversion layers (average $d \theta_{e}^{*} / d z=0.07 \mathrm{~K} \mathrm{~m}^{-1}>0$ ), showing stable layers were present in that region. Thus, conditions that induce an internal gravity wave from a gust front that generated from the rainband may have been satisfied.

The type of internal gravity wave includes solitary wave and bore. Factors that determine the type of gravity wave, solitary wave, and/or bore include the depth and stability of the stable layer (Haase and Smith 1989). The primary difference between a solitary wave and a bore is that upward parcel displacements are long-lasting in the wake of the bore hydraulic jump, whereas the net parcel displacement for a solitary wave is negligible across the width of the disturbance (Christie et al. 1978; Knupp 2006).

The system observed in the present study could have been caused by a solitary wave because it has an up-down couplet structure. In addition, Rott- 
man and Einaudi (1993) presented plots showing the horizontal perturbation of wind speed aloft in the propagation direction of a solitary wave gradually increases and then decreases with time at a single location, which agrees with our observation (Fig. 11b). Thus, the gust front from the rainband might have propagated into the stable layer, lifted an inversion layer on the top of the stable layer, and generated a solitary wave as pointed out by Knupp (2006). Powell (1990) suggested that such gust fronts may be too shallow to detect in many cases. However, a solitary wave generated from a gust front may be detectable by the fact that it propagates along an elevated inversion layer (Knupp 2006). In fact, the second thin-line echo did not separate off from the outer rainband but appeared ahead of the rainband in the radar reflectivity field, suggesting that it was generated after the gust front intersected the stable layer.

Additional support for our hypothesis is provided from the wind profiler and radiosonde observations. Rottman and Einaudi (1993) indicated that the solitary wave can propagate if there is a deep enough region of negative $K^{2}$ (or even small positive values of $K^{2}$, where $K$ is the Scorer parameter) above the wave. They also showed that a layer of low Brunt-Väisälä frequency, $N$, can also act as a reflector of the wave. Their results suggest that negative layers of $N^{2}$ and $K^{2}$ with depths of more than $700 \mathrm{~m}$ can act as a duct for a solitary wave that propagates more than $200 \mathrm{~km}$ for 6 hours (Smith and Morton 1984). On the other hand, their results also show that positive $N^{2}$ less than $10^{-3} \mathrm{~s}^{-2}$ with a depth of more than $1000 \mathrm{~m}$ cannot act as a duct. Recently, Adachi et al. (2004b) showed that a negative layer of $N^{2}$ with a depth of about $50 \mathrm{~m}$ can act as a duct for a weak solitary wave with vertical velocities within or equal to $\pm 0.3 \mathrm{~m} \mathrm{~s}^{-1}$ that propagates for at least $15 \mathrm{~min}$.

Plots of $N^{2}$ and $K^{2}$ derived from the radiosonde and profiler observations are shown in Figs. 13a and 13b, respectively (See Appendix C for calculations of $N^{2}$ and $K^{2}$ ). Figure 13a shows a region of low $N^{2}$ at $2000 \mathrm{~m}$ above the ground. However, the region of negative $N^{2}$ is not deep $(\sim 100 \mathrm{~m})$ enough to trap all the wave energy with vertical velocities exceeding $\pm 2.5 \mathrm{~m} \mathrm{~s}^{-1}$. Thus, it is unlikely that this region could act as a waveguide. On the other hand, Fig. $13 \mathrm{~b}$ shows a region of negative $K^{2}$ with a depth of more than $400 \mathrm{~m}$ at about $3.5-4 \mathrm{~km}$ exists just above the top of the strong up-down couplet observed with the profiler (Fig. 12b). Since
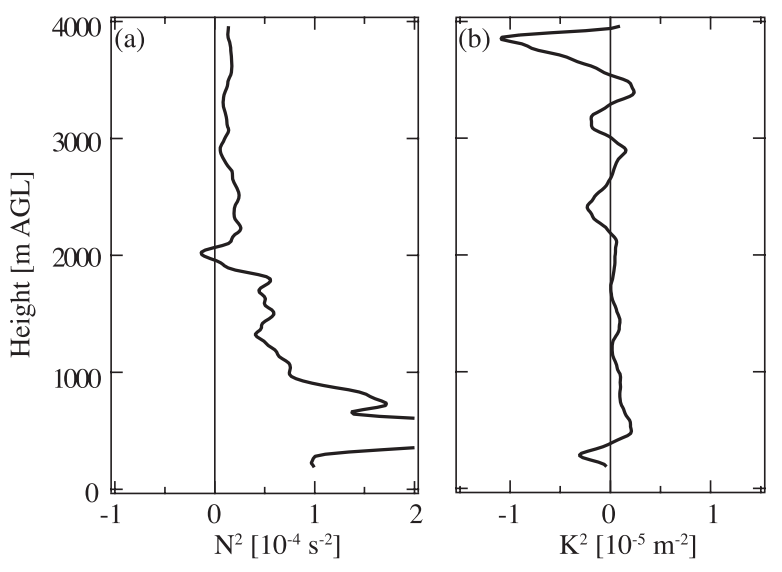

Fig. 13. (a) Profile of the square of the Brunt-Väisälä frequency $\left(N^{2}\right)$ at 2209 JST on 1 October 2002. (b) Profile of the square of the Scorer parameter $\left(K^{2}\right)$ averaged over 2220-2230 JST on 1 October 2002.

this region is deep, it is likely that this layer could act as a waveguide for the solitary wave to propagate for about 20 min (Fig. 8).

As pointed out by Crook (1986) and Crook (1988), the most common reason for a layer of negative $K^{2}$ is velocity shear in the lower atmosphere. In our case, strong winds $\left(>30 \mathrm{~m} \mathrm{~s}^{-1}\right)$ at altitudes more than $3500 \mathrm{~m}$ at 2225-2240 JST observed with the profiler (Fig. 10) enhanced the velocity shear and caused the deep region of low $K^{2}$. This strong wind region could be part of the high winds aloft observed with the Doppler radar. This means that the high winds aloft might have contributed to propagate the solitary wave.

\section{Concluding remarks}

This paper analyzed two thin-line echoes embedded within Typhoon Higos (0221) that passed across the Kanto Plain on 1 October 2002. Gusts with wind speeds comparable to those of F1 tornadoes accompanied the first thin-line echo. Data from Doppler radar, tower, and wind profiler observations at the MRI site and from a surface observation network revealed that the first thin-line echo was caused by a gust front, and the second thin-line echo was caused by a solitary wave.

Although it was demonstrated that the first thinline echo was associated with a gust front, this gust front cannot be categorized as a so-called thunderstorm gust front, because it had no parent convective storm that generated strong downdrafts be- 
hind; rather, observations showed that the gust front in the present study was generated in a weak precipitation region between the typhoon center and a trailing outer rainband to the southwest. Doppler radar and wind profiler observations suggest that relatively strong downdrafts $\left(\sim 4 \mathrm{~m} \mathrm{~s}^{-1}\right)$ in the weak precipitation region and large momentum transported by the downdrafts from aloft $(\sim 4 \mathrm{~km})$ to lower levels produced and maintained near-surface high winds behind the gust front.

In contrast, the solitary wave associated with the second thin-line echo likely developed as another gust front that generated from an outer rainband to the south of the typhoon center met a stable layer formed by the cold outflow behind the first gust front associated with the first thin-line echo. We also found a region of low $K^{2}$ just above the solitary wave, indicating that this region could act as a waveguide.

\section{Acknowledgments}

The first author would like to express his gratitude to Professor S. Fukao and Associate Professor H. Hashiguchi of the Research Institute for Sustainable Humanosphere (RISH) in Kyoto University for their guidance and valuable comments on this study. He also thanks Professors T. Satomura, T. Tsuda, S. Yoden and M. Shiotani of Kyoto University for constructive suggestions; and Dr. T. Inoue of the MRI for providing information on GMS-5. The authors collectively thank M. Ueno for the comments on the analysis of the solitary wave; Y. Tanaka for providing DRAFT (Tanaka and Suzuki 2000) to analyze the Doppler radar data; H. Yamauchi for the Doppler radar data used in this study; M. Kumamoto and T. Kaneko and stuff of the Aerological Observatory for radiosonde and surface data measured at the AO; and Dr. S. Shimizu of the Japan Aerospace Exploration Agency (JAXA) for the disdrometer data measured at Sendai, Kyushu, Japan. The authors also thank anonymous reviewers who made many essential comments that improved this work substantially.

\section{Appendix A}

Estimation of vertical air motion from the reflectivities and Doppler velocities measured by the
profiler in precipitation

The vertical wind component $w_{\text {air }}$ is customarily determined from the observed mean or median Doppler velocity $W_{o b s}$ of raindrops using a reflectivity-estimated terminal velocity and a relationship proposed by Joss and Waldvogel (1970) as

$$
w_{\text {air }}=W_{o b s}+2.6 Z^{0.107}\left(\frac{\rho}{\rho_{0}}\right)^{0.4} \text {, }
$$

where $w_{\text {air }}$ and $W_{\text {obs }}$ are in $\mathrm{m} \mathrm{s}^{-1}$ (positive upward), $Z$ is reflectivity in $\mathrm{mm}^{6} \mathrm{~m}^{-3}$ at given height, and $\rho_{0}$ $(\rho)$ is air density at surface (at given height) in $\mathrm{kg} \mathrm{m}^{-3}$. The parenthetical term, which was proposed by Foote and du Toit (1969), serves to increase the terminal velocity of raindrops with height as density decreases (Ray 1990). This method is accurate to within $\pm 1 \mathrm{~m} \mathrm{~s}^{-1}$ and can be used for reflectivities $(Z)$ in the range from 10 to $53 \mathrm{dBZ}$, which correspond to rain intensities from $0.2 \mathrm{~mm} \mathrm{~h}^{-1}$ to $74 \mathrm{~mm} \mathrm{~h}^{-1}$. Equations (including A1) that consider the $w_{\text {air }}-Z$ relation are discussed in Atlas et al. (1973).

In the present study, the air density profile derived from the radiosonde measurement at 2209 JST was used. In addition, a radar calibration factor for the MRI profiler required for reflectivity calculations was determined from data obtained during the X-Baiu-01 field campaign at Sendai, in Kyushu, Japan (Adachi et al. 2004a), during which the profiler and a Distromet, Inc., RD-69 JossWaldvogel disdrometer were collocated.

\section{Appendix B}

\section{Calculation of the Froude number}

The Froude number $(F r)$ is derived from the speed of propagation predicted from gravity current theory $\left(C_{g c}\right)$ by

$$
C_{g c}=\operatorname{Fr}\left(\frac{p_{c}-p_{w}}{\rho_{w}}\right)^{1 / 2},
$$

where $p_{c}\left(p_{w}\right)$ is the observed surface pressure of the cold (warm) air behind (ahead of) the leading edge of the gravity current, while $\rho_{w}$ is layer-mean density of the warm air ahead of the leading edge of the gravity current (Koch and Clark 1999).

In the present study, it is difficult to distinguish the exact effect of the cold air and that of the typhoon in the observed surface pressure (Fig. 9). Thus, we use the layer-mean density instead of the surface pressure. The hydrostatic low for the cold and warm air masses is given by,

$$
\Delta p=p_{c}-p_{w}=g d_{0}\left(\rho_{c}-\rho_{w}\right),
$$

where $g$ is gravitational acceleration, $\rho_{c}$ is layermean density of the cold air behind the leading 
edge of the gravity current and $d_{0}$ is mean depth of the cold air. Substitution of equation (A3) into (A2) provides,

$$
C_{g c}=\operatorname{Fr}\left(g d_{0} \frac{\rho_{c}-\rho_{w}}{\rho_{w}}\right)^{1 / 2} .
$$

The values of density and mean depth of the cold air can be derived from radiosonde measurements.

Figure 3 shows that there were two distinct inversion layers, from $386 \mathrm{~m}$ to $537 \mathrm{~m}$ and from $767 \mathrm{~m}$ to $810 \mathrm{~m}$ above the ground $(\mathrm{AGL}=\mathrm{MSL}-30 \mathrm{~m})$ at 2208 JST. These inversions were likely associated with the cold airflow behind the first thin-line echo because the radiosonde observation was made well into the body of the cold air (Fig. 5d). Since the wind speed associated with the low-level high winds exceeded $30 \mathrm{~m} \mathrm{~s}^{-1}$ at the altitude of $720 \mathrm{~m}$ AGL at 2208 JST (Figs. 11a and 12a), it is likely that the bottom of the second inversion $(767 \mathrm{~m}$ AGL) corresponds to the mean depth of the cold airflow. The layer-mean densities of the cold and warm air derived from the radiosonde measurements are $1.109 \mathrm{~kg} \mathrm{~m}^{-3}$ and $1.092 \mathrm{~kg} \mathrm{~m}^{-3}$, respectively.

It is also necessary to account for the effect of tailwind, which will accelerate the movement of the gravity current by $\sim 62 \%$ of the head wind speed (Simpson and Britter 1980). The profiler and tower observations show that the prefrontal tailwind averaged over the mean depth of the cold airflow and over $10 \mathrm{~min}$ just ahead of the descendent of the high winds aloft at 2135 JST (Fig. 10) was $18.2 \mathrm{~m} \mathrm{~s}^{-1}$ in the front propagation direction. This results in a corrected gravity current speed prediction of $8.2 \mathrm{~m} \mathrm{~s}^{-1}$, from which we obtain the Froude number of 0.76 .

\section{Appendix C}

\section{Calculation of the score parameter}

The Scorer parameter, $K$, is often used as a parameter for a wave duct because waves can be trapped below the region of negative $K^{2} . K$ is given by

$$
\begin{aligned}
K^{2}(z)= & \frac{N^{2}}{\left(u_{0}-c\right)^{2}}-\frac{u_{0}^{\prime \prime}}{\left(u_{0}-c\right)}-\frac{1}{2}\left(\frac{\rho_{0}^{\prime}}{\rho}\right)^{\prime} \\
& -\left(\frac{1}{2} \frac{\rho_{0}^{\prime}}{\rho}\right)^{2}-\frac{u_{0}^{\prime} \rho_{0}^{\prime} / \rho_{0}}{u_{0}-c},
\end{aligned}
$$

where $N$ is the Brunt-Väisälä frequency defined as

$$
N^{2}=\frac{g}{\theta_{v}} \frac{d \theta_{v}}{d z}
$$

$u_{0}$ is the background velocity, $c$ is the phase speed of the wave, $\rho_{0}(\rho)$ is air density at surface (at given height) in $\mathrm{kg} \mathrm{m}^{-3}$ and $\theta_{v}$ is the virtual potential temperature. In the Bousinesq approximation, since the variation of the background density is negligible, only the first two terms in the equation are kept (Rottman and Einaudi 1993).

For the solution of (A5), the Brunt Väisälä frequency $N$ can be derived from the profile of the virtual potential temperature which is derived from the $T_{v}$ profile measured with the radiosonde launched at 2209 JST. In the derivation of the virtual potential temperature from the $T_{v}$ profile, we used the surface data recorded at the AO as a boundary condition. The phase speed $c$ and propagation direction of the solitary wave are assumed equal to those of the second thin-line echo $\left(16.2 \mathrm{~m} \mathrm{~s}^{-1}\right.$ and $\left.346^{\circ}\right)$. The background velocity $u_{0}$ is the wind component in the direction of propagation of the solitary wave. For $u_{0}$, we used the profile of wind speed in the propagation direction of the second thin-line echo derived from the profiler averaged over 2220-2230 JST, just before the second temperature depression period $\left(\mathrm{P}_{2}\right)$.

\section{References}

Adachi, A., T. Kobayashi, and T. Kato, 2004a: Dual wind profiler observations of a line-shaped convective system in southern Kyushu, Japan. J. Meteor. Soc. Japan, 82, 725-743.

Adachi, A., W. L. Clark, L. M. Hartten, K. S. Gage and T. Kobayashi, 2004b: An observational study of a shallow gravity current triggered by katabatic flow. Ann. Geophys., 22, 3937-3950.

Adachi, A., T. Kobayashi, K. S. Gage, D. A. Carter, L. M. Hartten, W. L. Clark, and M. Fukuda, 2005: Evaluation of three-beam and four-beam profiler wind measurement techniques using a five-beam wind profiler and collocated meteorological tower. J. Atmos. Oceanic Technol., 22, 1167-1180.

Ahrens, C. D., 2003: Hurricanes, Meteorology Today, An introduction to weather, climate, and the environment, Brooks/Cole-Thomson Learning, 437443.

Atlas, D., R. C. Srivastava, and R. S. Sekhon, 1973: Doppler radar characteristics of precipitation at vertical incidence. Rev. Geophys. Space Phys., 2, 1035.

Charba, J., 1974: Application of gravity current model to analysis of squall-line gust front. Mon. Wea. Rev., 102, 140-156.

Christie, D. R., K. J. Muirhead, and A. L. Hales, 1978: 
On solitary waves in the atmosphere. J. Atmos. Sci., 35, 805-825.

Corfidi, S. F., 2003: Cold pools and MCS propagation: Forecasting the motion of downwind-developing MCSs. Wea. Forecasting., 18, 997-1017.

Cressman, G. P., 1959: An operational objective analysis system. Mon. Wea. Rev., 87, 367-374.

Crook, A., and J. D. Tuttle, 1994: Numerical simulations initialized with radar-derived winds. Pail II: Forecasts of three gust-front cases. Mon. Wea. Rev., 122, 1204-1217.

Crook, N. A., 1986: The effect of ambient stratification and moisture on the motion of atmospheric undular bores. J. Atmos. Sci., 43, 171-181.

Crook, N. A., 1988: Trapping of low-level internal gravity waves. J. Atmos. Sci., 45, 1533-1541.

Curry, R. A., and M. I. Biggerstaff, 2005: Dual-Doppler analysis of hurricane Isabel at landfall: A research experience for undergraduates. 32nd Conf. on $\mathrm{Ra}$ dar Meteorology, Albuquerque, JP2J.2.

Droegemeier, K. K., and R. B. Wilhelmson, 1987: Numerical simulation of thunderstorm outflow dynamics. Part I: Outflow sensitivity experiments and turbulence dynamics. J. Atmos. Sci., 44, 1180-1210.

Emanuel, K., S. Ravela, E. Vivant, and C. Risi, 2006: A statistical deterministic approach to hurricane risk assessment. Bull. Amer. Meteor. Soc., 87, 299-314.

Foote, G. B., and P. S. du Toit, 1969: Terminal velocity of raindrops aloft. J. Appl. Meteor., 8, 249-253.

Friedrich, K., D. E. Kingsmill, and C. R. Young, 2005: Misocyclone characteristics along Florida gust fronts during CaPE. Mon. Wea. Rev., 133, 33453367.

Gage, K. S., 1990: Radar observations of the free atmosphere: Structure and dynamics, Radar in Meteorology, D. Atlas, Ed., Amer. Meteor. Soc., 534565.

Gilmore, M. S., and L. J. Wicker, 1998: The influence of midtropospheric dryness on supercell morphology and evolution. Mon. Wea. Rev., 126, 943-958.

Glickman, T. S. E., 2000: Glossary of Meteorology. 2nd ed. Amer. Meteor. Soc., 855 pp.

Goff, R. C., 1976: Vertical structure of thunderstorm outflows. Mon. Wea. Rev., 104, 1429-1440.

Haase, S. P., and R. K. Smith, 1989: The numerical simulation of atmospheric gravity currents. Part II: Environments with stable layers. Geophys. Astrophys. Fluid Dyn., 46, 35-51.

Hagemeyer, B. C., 1997: Peninsular Florida tornado outbreaks. Wea. Forecasting., 12, 399-427.

Halverson, J. B., J. Simpson, G. Heymsfield, H. Pierce, T. Hock, and L. Ritchie, 2006: Warm core structure of Hurricane Erin diagnosed from high altitude dropsondes during CAMEX-4. J. Atmos. Sci., 63, 309-324.

Hanafusa, T., T. Fujitani, N. Banno, and H. Uozu, 1979: On the meteorological tower and its observational system at Tsukuba science city. Tech. Reports of the MRI, $50 \mathrm{pp}$.

Hashiguchi, H., S. Fukao, Y. Moritani, T. Wakayama, and S. Watanabe, 2004: A lower troposphere radar: $1.3-\mathrm{GHz}$ active phased-array type wind profiler with RASS. J. Meteor. Soc. Japan, 82, 915931.

Hawkins, H. F., and S. M. Imbembo, 1976: The structure of a small, intense Hurricane-Inez 1966. Mon. Wea. Rev., 104, 418-442.

Hayashi, T., 2008: Transition of disaster by typhoon (in Japanese). Tenki, 55, 369-374.

Houze, R. A., Jr., 1993: Cloud Dynamics. Academic press, $573 \mathrm{pp}$.

JMA, 2003: Annual Report on Activities of the RSMC Tokyo-Typhoon Center 2002. 71 pp.

Joss, J., and D. Waldvogel, 1970: Raindrop size distributions and Doppler velocities. 14th Conf. on Radar Meteorology, Tucson, AZ, 153-156.

Kingsmill, D. E., and N. A. Crook, 2003: An observational study of atmospheric bore formation from colliding density currents. Mon. Wea. Rev., 131, 2985 3002 .

Klingle, D. L., D. R. Smith, and M. M. Wolfson, 1987: Gust front characteristics as detected by Doppler radar. Mon. Wea. Rev., 115, 905-918.

Knupp, K., 1987: Downdrafts within high plains cumulonimbi. Part I: General kinematic structure. $J$. Atmos. Sci., 44, 987-1008.

Knupp, K., 2006: Observational analysis of a gust front to bore to solitary wave transition within an evolving nocturnal boundary layer. J. Atmos. Sci., 63, 2016-2035.

Kobayashi, T., and A. Adachi, 2005: Retrieval of arbitrarily shaped raindrop size distributions from wind profiler measurements. J. Atmos. Oceanic Technol., 22, 433-442.

Koch, S. E., and W. L. Clark, 1999: A nonclassical cold front observed during COPS-91: Frontal structure and the process of severe storm initiation. $J$. Atmos. Sci., 56, 2862-2890.

Kuchera, E. L., and M. D. Parker, 2006: Severe convective wind environments. Wea. Forecasting., 21, 595-612.

Lander, M. A., and C. P. Guard, 2001: Western north Pacific, north Indian Ocean, and southern hemisphere tropical cyclones of 1997. Mon. Wea. Rev., 129, 3015-3036.

Mahoney, W. P. I., 1988: Gust front characteristics and the kinematics associated with interacting thunderstorm outflows. Mon. Wea. Rev., 116, 1474-1492.

Martner, B. E., 1997: Vertical velocities in a thunderstorm gust front and outflow. J. Appl. Meteor., 36, 615-622.

McCaul, E. W. J., and M. L. Weisman, 1987: Observations of the hurricane "Danny" tornado outbreak of 16 August 1985. Mon. Wea. Rev., 115, 1206-1223. 
Miller, P. A., T. W. Schlatter, D. W. van de Kamp, M. F. Barth, and B. L. Weber, 1994: An unfolding algorithm for profiler winds. J. Atmos. Oceanic Technol., 11, 32-41.

Mueller, C. K., and R. E. Carbone, 1987: Dynamics of a thunderstorm outflow. J. Atmos. Sci., 44, 18791898.

Muramatsu, T., 2008: Starting poit of disaster prevention of typhoon -50 years since Isewan Typhoon (in Japanese). Tenki, 55, 362-369.

Neiman, P. J., and R. M. Wakimoto, 1999: The interaction of a Pacific cold front with shallow air masses east of the Rocky Mountains. Mon. Wea. Rev., 127, 2102-2127.

Novlan, D. J., and W. M. Gray, 1974: Hurricanespawned tornadoes. Mon. Wea. Rev., 102, 476-488.

Orlanski, I., 1975: A rational subdivision of scales for atmospheric processes. Bull. Amer. Meteor. Soc., 56, 527-530.

Powell, M. D., 1990: Boundary layer structure and dynamics in outer hurricane rainbands. Part I: Mesoscale rainfall and kinematic structure. Mon. Wea. Rev., 118, 891-917.

Ralph, F. M., 1995: Using radar-measured radial vertical velocities to distinguish precipitation scattering from clear-air scattering. J. Atmos. Oceanic Technol., 12, 257-267.

Ralph, F. M., P. J. Neiman, D. W. van de Kamp, and D. C. Law, 1995: Using spectral moment data from NOAA's 404-MHz radar wind profilers to observe precipitation. Bull. Amer. Meteor. Soc., 76, 17171739.

Ray, P., 1990: Convective dynamics, Radar in Meteorology, D. Atlas. Ed., Amer. Meteor. Soc., 348390.

Rottman, J., and F. Einaudi, 1993: Solitary waves in the atmosphere. J. Atmos. Sci., 50, 2116-2136.

Saito, A., 1992: Mesoscale analysis of typhoon-associated tormado outbreaks in Kyushu Island on 13 October 1980. J. Meteor. Soc. Japan, 70, 43-55.

Simpson, J., and R. E. Britter, 1979: The dynamics of the head of a gravity current advancing over a horizontal sufrace. J. Fluid Mech., 94, 477-495.

Simpson, J. E., 1997: Gravity Currents in the Environment and the Laboratory. Cambridge university press, 244 pp.

Simpson, J. E., and R. E. Britter, 1980: A laboratory model of an atmospheric mesofront. Quart. J. Roy. Meteor. Soc., 106, 485-500.
Smith, J. S., 1965: The hurricane-tornado. Mon. Wea. Rev., 93, 453-459.

Smith, R. K., and B. R. Morton, 1984: An observational study of northeasterly 'morning glory' wind surges. Aust. Meteor. Mag., 32, 155-175.

Smith, R. K., and M. J. Reeder, 1988: On the movement and low-level structure of cold fronts. Mon. Wea. Rev., 116, 1927-1944.

Tanaka, Y., and O. Suzuki, 2000: Development of a radar data analysis software, "Draft". Proc. of the Spring Conference of Japan Meteor. Soc., 303.

Van Zandt, T. E., 2000: A brief history of the development of wind-profiling or MST radars. Ann. Geophys., 18, 740-749.

Wakimoto, R. M., 1982: The life cycle of thunderstorm gust fronts as viewed with Doppler radar and rawinsonde data. Mon. Wea. Rev., 110, 1060-1082.

Wakimoto, R. M., 2003: Convectively driven high wind events, Severe convective storms, Charles A. Doswell III, Ed., Amer. Meteor. Soc., 28, 255-298.

Wakimoto, R. M., and B. L. Bosart, 2000: Airborne radar observations of a cold front during FASTEX1. Mon. Wea. Rev., 128, 2447-2470.

Weiss, C. C., and H. B. Bluestein, 2002: Airborne pseudodual Doppler analysis of a dryline-outflow boundary intersection. Mon. Wea. Rev., 130, 1207-1226.

Westcott, N., 1984: A historical perspective on cloud mergers. Bull. Amer. Meteor. Soc., 65, 219-226.

Westcott, N. E., 1994: Merging of convective clouds: Cloud initiation, bridging, and subsequent growth. Mon. Wea. Rev., 122, 780-790.

Willoughby, H. E., H. -L. Jin, S. J. Lord and J. M. Piotrowicz, 1984: Hurricane structure and evolution as simulated by an axisymmetric, nonhydrostatic numerical model. J. Atmos. Sci., 41, 1169-1186.

Wilson, J. W., and W. E. Schreiber, 1986: Initiation of convective storms at radar-observed boundarylayer convergence lines. Mon. Wea. Rev., 114, 2516-2536.

Xue, M., and W. J. Martin, 2006: A high-resolution modeling study of the 24 May 2002 dryline case during IHOP. Part II: Horizontal convective rolls and convective initiation. Mon. Wea. Rev., 134, $172-191$.

Yau, M. K., Y. Liu, D. -L. Zhang, and Y. Chen, 2004: A multiscale numerical study of Hurricane Andrew (1992). Part VI: Small-scale inner-core structures and wind streaks. Mon. Wea. Rev., 132, 14101433. 